\title{
Japan Renal Biopsy Registry and Japan Kidney Disease Registry: Committee Report for 2009 and 2010
}

\author{
Hitoshi Sugiyama $\cdot$ Hitoshi Yokoyama $\cdot$ Hiroshi Sato $\cdot$ Takao Saito $\cdot$ Yukimasa Kohda $\cdot$ Shinichi Nishi $\cdot$ \\ Kazuhiko Tsuruya $\cdot$ Hideyasu Kiyomoto $\cdot$ Hiroyuki Iida $\cdot$ Tamaki Sasaki $\cdot$ Makoto Higuchi $\cdot$ \\ Motoshi Hattori $\cdot$ Kazumasa Oka $\cdot$ Shoji Kagami $\cdot$ Tetsuya Kawamura $\cdot$ Tetsuro Takeda $\cdot$ Hiroshi Hataya $\cdot$ \\ Yuichiro Fukasawa - Atsushi Fukatsu $\cdot$ Kunio Morozumi $\cdot$ Norishige Yoshikawa Akira Shimizu \\ Hiroshi Kitamura • Yukio Yuzawa - Seiichi Matsuo • Yutaka Kiyohara • Kensuke Joh • Michio Nagata • \\ Takashi Taguchi • Hirofumi Makino - Committee for Standardization of Renal Pathological Diagnosis \\ and Committee for Kidney Disease Registry, Japanese Society of Nephrology, Japan
}

Received: 30 July 2012/Accepted: 18 November 2012/Published online: 6 February 2013

(C) Japanese Society of Nephrology 2013

\begin{abstract}
The Japan Renal Biopsy Registry (J-RBR) was started in 2007 and the Japan Kidney Disease Registry (J-KDR) was then started in 2009 by the Committee for Standardization of Renal Pathological Diagnosis and the Committee for the Kidney Disease Registry of the Japanese Society of Nephrology. The purpose of this report is to describe and summarize the registered data from 2009 and 2010. For the J-KDR, data were collected from 4,016 cases,
\end{abstract}

Electronic supplementary material The online version of this article (doi:10.1007/s10157-012-0746-8) contains supplementary material, which is available to authorized users.

\section{H. Sugiyama $\cdot$ H. Makino}

Department of Medicine and Clinical Science, Okayama

University Graduate School of Medicine, Dentistry, and

Pharmaceutical Sciences, Okayama, Japan

H. Yokoyama ( $\square)$

Division of Nephrology, Kanazawa Medical University School of Medicine, 1-1 Daigaku, Uchinada, Ishikawa 920-0293, Japan e-mail: h-yoko@kanazawa-med.ac.jp

H. Sato

Division of Nephrology, Tohoku University Graduate School of Medicine, Sendai, Japan

\section{T. Saito}

Division of Nephrology and Rheumatology, Department of Internal Medicine, Fukuoka University School of Medicine, Fukuoka, Japan

\section{Y. Kohda}

Department of Nephrology, Faculty of Life Sciences,

Kumamoto University, Kumamoto, Japan

Present Address:

Y. Kohda

Hikarinomori Clinic, Kumamoto, Japan including 3,336 (83.1\%) by the J-RBR and $680(16.9 \%)$ other cases from 59 centers in 2009, and from 4,681 cases including 4,106 J-RBR cases $(87.7 \%$ ) and 575 other cases $(12.3 \%)$ from 94 centers in 2010, including the affiliate hospitals. In the J-RBR, 3,165 native kidneys (94.9\%) and 171 renal grafts $(5.1 \%)$ and 3,869 native kidneys $(94.2 \%)$ and 237 renal grafts $(5.8 \%$ ) were registered in 2009 and 2010 , respectively. Patients younger than 20 years of age comprised $12.1 \%$ of the registered cases, and those 65 years and over comprised $24.5 \%$ of the cases with native kidneys in 2009 and 2010. The most common clinical diagnosis was chronic

S. Nishi

Division of Nephrology and Kidney Center, Kobe University

School of Medicine, Kobe, Japan

K. Tsuruya

Department of Integrated Therapy for Chronic Kidney Disease, Graduate School of Medical Sciences, Kyushu University,

Fukuoka, Japan

H. Kiyomoto

Division of Integrated Nephrology and Telemedicine,

Department of Community Medical Supports, Tohoku Medical

Megabank Organization, Tohoku University, Sendai, Japan

H. Iida

Department of Internal Medicine, Toyama Prefectural Central Hospital, Toyama, Japan

T. Sasaki

Division of Nephrology and Hypertension, Department of Internal Medicine, Kawasaki Medical School, Kurashiki, Japan

M. Higuchi

Division of Nephrology, Department of Internal Medicine, Shinshu University School of Medicine, Matsumoto, Japan 
nephritic syndrome $(55.4 \%$ and $50.0 \%$ in 2009 and 2010, respectively), followed by nephrotic syndrome $(22.4 \%$ and $27.0 \%$ ); the most frequent pathological diagnosis as classified by the pathogenesis was IgA nephropathy $(31.6 \%$ and $30.4 \%$ ), followed by primary glomerular diseases (except IgA nephropathy) $(27.2 \%$ and $28.1 \%)$. Among the primary glomerular diseases (except IgA nephropathy) in the patients with nephrotic syndrome, membranous nephropathy was the most common histopathology in $2009(40.3 \%)$ and minor glomerular abnormalities $(50.0 \%)$ were the most common in 2010 in native kidneys in the J-RBR. Five new secondary and longitudinal research studies by the J-KDR were started in 2009 and one was started in 2010.

Keywords Native kidney biopsy · Primary glomerulonephritis $\cdot \operatorname{IgA}$ nephropathy $\cdot$ Membranous nephropathy $\cdot$ Renal grafts $\cdot$ National registry

\section{Introduction}

The Japanese Society of Nephrology (JSN) established the Japan Renal Biopsy Registry (J-RBR) in 2007, and it conducted analyses for 2007 and 2008 [1]. In 2009, the JSN started the Japan Kidney Disease Registry (J-KDR) to record clinically-diagnosed cases in addition to the J-RBR. Participation in the J-KDR, including the J-RBR, was

M. Hattori

Department of Pediatric Nephrology, Tokyo Women's Medical University, School of Medicine, Tokyo, Japan

K. Oka

Department of Pathology, Hyogo Prefectural Nishinomiya

Hospital, Hyogo, Japan

S. Kagami

Department of Pediatrics, The Institute of Health Bioscience,

The University of Tokushima Graduate School, Tokushima,

Japan

T. Kawamura

Department of Medicine, Division of Kidney and Hypertension,

Jikei University School of Medicine, Tokyo, Japan

T. Takeda

Division of Clinical Nephrology and Rheumatology, Niigata

University Graduate School of Medical and Dental Sciences,

Niigata, Japan

Present Address:

T. Takeda

Department of Nephrology, Dokkyo Medical University

Koshigaya Hospital, Koshigaya, Japan

H. Hataya

Department of Nephrology, Tokyo Metropolitan Children's

Medical Center, Tokyo, Japan requested from appointed clinical training hospitals of the JSN and the Japanese Society for Dialysis Therapy in an attempt to extend the registry nationwide. In this report, the detailed data of the J-RBR and the frequencies of the different clinical diagnoses in the J-KDR registered from January to December of 2009 and 2010 are summarized.

\section{Subjects and methods}

Registry system and patients

This report includes the data from patients included in the J-RBR and J-KDR (J-RBR/J-KDR), registered prospectively from January 2009 to December 2010. The patients' data, including age, gender, laboratory data, and the clinical and pathological diagnoses, were recorded at each institution and registered on the web page of the J-RBR/JKDR utilizing the Internet Data and Information Center for Medical Research (INDICE) system of the University Hospital Medical Information Network (UMIN), as described previously [1]. The ethics committee of the JSN and that of Okayama University Graduate School of Medicine, Dentistry, and Pharmaceutical Sciences comprehensively approved the study, and a local committee of participating centers and their affiliate hospitals individually approved the study. Written informed consent was

Y. Fukasawa

Department of Pathology, KKR Sapporo Medical Center,

Sapporo, Japan

A. Fukatsu

Department of Nephrology, Kyoto University Graduate School of Medicine, Kyoto, Japan

Present Address:

A. Fukatsu

Department of Nephrology, Yachiyo Hospital, Anjo, Japan

K. Morozumi

Kidney Center, Japanese Red Cross Nagoya Daini Hospital,

Nagoya, Japan

N. Yoshikawa

Department of Pediatrics, Wakayama Medical University, School of Medicine, Wakayama, Japan
A. Shimizu
Department of Pathology, Nippon Medical School, Tokyo, Japan
H. Kitamura
Department of Pathology, Clinical Research Center, National Hospital Organization Chiba East National Hospital, Chiba, Japan 
obtained from the patients at the time of biopsy or at the time they were registered to participate in the study. The $\mathrm{J}-\mathrm{RBR} / \mathrm{J}-\mathrm{KDR}$ is registered in the Clinical Trial Registry of UMIN (Registered Number UMIN000000618).

Clinical or renal histopathological diagnosis and laboratory data

Three classifications, including the clinical diagnosis, histological diagnosis based on the pathogenesis, and histological diagnosis based on a histopathological examination, were made for each case included in the J-RBR, as described previously [1]. Of these classifications, the clinical diagnosis alone was selected for the J-KDR. The definition of each diagnosis was based on the clinical syndromes and renal histopathology, as described previously [2]. IgA nephropathy (IgAN) (Berger disease) was separated from primary glomerular diseases on the basis of basic glomerular alterations in the classification of glomerular diseases by the World Health Organization [2]. In 2010, hemolytic uremic syndrome and thrombotic thrombocytopenic purpura (HUS/TTP), congenital anomalies of the kidney and urinary tract (CAKUT) and polycystic kidney disease (PKD) were added to the classification of the clinical diagnosis on the case record (Table S1). The clinical data, including the results of the urinalysis, daily proteinuria, serum creatinine concentrations, total protein,

\section{Y. Yuzawa}

Department of Nephrology, Fujita Health University School of Medicine, Toyoake, Japan

S. Matsuo

Department of Nephrology, Nagoya University Graduate School of Medicine, Nagoya, Japan

\section{Y. Kiyohara}

Department of Environmental Medicine, Graduate School of

Medical Sciences, Kyushu University, Fukuoka, Japan

K. Joh

Division of Pathology, Sendai Shakai Hoken Hospital, Sendai, Japan

\section{Nagata}

Molecular Pathology, Biomolecular and Integrated Medical Sciences, Graduate School of Comprehensive Human Sciences, University of Tsukuba, Tsukuba, Japan

\section{T. Taguchi}

Department of Pathology, Nagasaki University Graduate School of Biomedical Sciences, 1-12-4 Sakamoto, Nagasaki 852-8523, Japan

\section{Present Address:}

T. Taguchi $(\bowtie)$

Department of Pathology, Nagasaki Municipal Hospital,

Nagasaki, Japan

e-mail: taguchi@nagasaki-u.ac.jp albumin, and the total cholesterol values, were always recorded, while the systolic and diastolic blood pressure, prescription use of anti-hypertensive agents, hemoglobin A1c, and presence of diabetes mellitus were optionally recorded. The estimated glomerular filtration rate was calculated as described previously [3]. The frequency of the diseases are here described in general, but the clinical data were also analyzed separately for cases of IgAN, which is the most common renal disease in Japan $[1,4,5]$.

\section{Statistical analyses}

Data are expressed as the mean $\pm \mathrm{SD}$ for continuous parametric data, medians and interquartile ranges for continuous non-parametric data, and frequencies for categorical data. The statistical analyses were performed using the JMP software program, version 8 (SAS Institute Inc., Cary, NC, USA).

\section{Results}

Baseline characteristics of the J-RBR/J-KDR participants in 2009 and 2010

The numbers of participating facilities and registered renal biopsies or cases without renal biopsies in the registry in 2009 and 2010 are shown in Table 1. The J-KDR was started in 2009 and the number of participating facilities increased by 34 compared to 2008 , reaching a total of 57 facilities in the J-RBR and 59 facilities in the J-KDR. The number of total renal biopsies increased to 3,336 in 2009, which was 1,754 more biopsies than in the previous year [1], and in 2010 it further increased to 4,106 in the J-RBR. The number of other cases (not in the J-RBR), which corresponds to the cases without renal biopsies but diagnosed by clinical findings, was 680 and 575 in 2009 and 2010 , respectively. The average age of this cohort was more than 10 years higher than that of the J-RBR in each year (Table 1).

The number of native kidney biopsies increased; however, that of renal graft biopsies registered in 2009 slightly decreased compared to 2008 (Table 2). The distribution of age ranges showed a peak distribution in the seventh decade in both genders for native kidneys (Table 3). Patients younger than 20 years of age comprised $12.1 \%$ and $10.3 \%$ of the cases, and those 65 years of age and over comprised $24.5 \%$ and $4.7 \%$ of the native kidney and renal grafts, respectively, during the 2-year period (2009 and 2010). In the patients who underwent renal grafts, both the average age and the peak distribution of age ranges were younger than those of patients who underwent native kidney biopsies (Tables 2, 3). 
Table 1 The number of participated renal centers and registered renal biopsies or other cases without renal biopsies in J-RBR/J-KDR 2009 and 2010

\begin{tabular}{|c|c|c|c|c|c|c|}
\hline & \multicolumn{3}{|l|}{2009 J-KDR } & \multicolumn{3}{|l|}{$2010 \mathrm{~J}-\mathrm{KDR}$} \\
\hline & $\mathrm{J}-\mathrm{RBR}$ & Other cases ${ }^{\mathrm{a}}$ & Total & $J-R B R$ & Other cases $^{\mathrm{a}}$ & Total \\
\hline Renal centers $(n)^{\mathrm{b}}$ & $57^{\mathrm{c}}$ & - & 59 & 83 & - & 94 \\
\hline Total biopsies or cases $(n)$ & $3,336^{\mathrm{d}}(83.1 \%)$ & $680(16.9 \%)$ & $4,016(100.0 \%)$ & $4,106(87.7 \%)$ & $575(12.3 \%)$ & $4,681(100.0 \%)$ \\
\hline Average age (years) & $46.7 \pm 19.9$ & $58.1 \pm 17.8$ & $48.7 \pm 20.0$ & $46.7 \pm 20.6$ & $56.8 \pm 21.1$ & $47.9 \pm 20.9$ \\
\hline Male $(n)$ & $1,787(53.6 \%)$ & $418(61.5 \%)$ & $2,205(54.9 \%)$ & $2,183(53.2 \%)$ & $335^{\mathrm{e}}(58.3 \%)$ & $2,518^{\mathrm{e}}(53.8 \%)$ \\
\hline Female $(n)$ & $1,549(46.4 \%)$ & $262(38.5 \%)$ & $1,811(45.1 \%)$ & $1,923(46.8 \%)$ & $238^{\mathrm{e}}(41.4 \%)$ & $2,161^{\mathrm{e}}(46.2 \%)$ \\
\hline
\end{tabular}

$J-R B R$ Japan Renal Biopsy Registry, J-KDR Japan Kidney Disease Registry

Note that J-RBR started in 2007 and J-KDR started in 2009

a Other cases include patients diagnosed by clinical findings without renal biopsies

b The number represents principal institutions having affiliate hospitals. All of the participated institutions and hospitals in the J-RBR and J-KDR in 2009 and 2010 are shown in the "Appendix". The number of renal centers in total is based on the registration of cases without renal biopsies but diagnosed by clinical findings in addition to that of data with renal biopsy in J-RBR

c Increase of 34 when compared to the number in J-RBR 2008

${ }^{\mathrm{d}}$ Increase of 1,754 when compared to the number in J-RBR 2008

e No registered data for gender in 2 cases

The frequency of clinical diagnoses in the J-RBR

Three classifications, the clinical diagnosis, histological diagnosis based on the pathogenesis, and the histological diagnosis based on a histopathological examination, were included in the J-RBR database, while the clinical diagnosis alone was registered for the other cases. In the J-RBR, a clinical diagnosis of chronic nephritic syndrome was the most common, followed by nephrotic syndrome, in both total biopsies and native kidneys in 2009 and 2010, which was similar to the findings in 2007 and 2008 (Table 4) [1]. In native kidneys, more than half of the cases that were registered had chronic nephritic syndrome. The age distribution according to the classification of clinical diagnoses in native kidneys in the J-RBR in 2009 and 2010 was analyzed, and cases with rapidly progressive nephritic syndrome exhibited the highest mean age while cases with inherited renal diseases showed the youngest mean age (Table 5).

The frequency of pathological diagnoses in the J-RBR

The pathological diagnoses were classified based on the pathogenesis (Table 6) and histopathology (Table 7). In the classification of the pathogenesis, IgAN was diagnosed most frequently (31.6\%), followed by primary glomerular disease other than IgAN (27.2\%) in native kidneys in both 2009 and 2010 (Table 6). Similar frequencies of IgAN, primary glomerular disease other than IgAN and diabetic nephropathy were observed in the combined data for 2007 and 2008 [1]. In the pathological diagnosis classified based on the histopathology in native kidney biopsies, mesangial
Table 2 The number of registered renal biopsies in J-RBR 2009 and 2010

\begin{tabular}{llll}
\hline Years & 2009 & 2010 & Total \\
\hline Native kidneys, $n(\%)$ & $3,165^{\mathrm{a}}(94.9)$ & $3,869(94.2)$ & $7,034(94.5)$ \\
Average age (years) & $47.0 \pm 20.1$ & $47.1 \pm 20.8$ & $47.1 \pm 20.5$ \\
Median age (years) & $50(30-64)$ & $49(31-65)$ & $49(30-64)$ \\
Male, $n(\%)$ & $1,671(52.8)$ & $2,035(52.6)$ & $3,706(52.7)$ \\
Female, $n(\%)$ & $1,494(47.2)$ & $1,834(47.4)$ & $3,328(47.3)$ \\
Renal grafts, $n(\%)$ & $171^{\mathrm{b}}(5.1)$ & $237(5.8)$ & $408(5.5)$ \\
Average age (years) & $40.9 \pm 15.0$ & $41.3 \pm 15.4$ & $41.1 \pm 15.2$ \\
Median age (years) & $43(31-52)$ & $41(33-54)$ & $42(32-53)$ \\
Male, $n(\%)$ & $116(67.8)$ & $148(62.4)$ & $264(64.7)$ \\
Female, $n(\%)$ & $55(32.2)$ & $89(37.6)$ & $144(35.3)$ \\
\hline
\end{tabular}

${ }^{a}$ Increase of 1,765 when compared to the number in J-RBR 2008

b Decrease of 11 when compared to the number in J-RBR 2008

proliferative glomerulonephritis was the most frequently observed disease, representing $42.5 \%$ and $35.8 \%$ of the cases in 2009 and 2010 (Table 7).

Primary glomerular disease (except IgAN) and nephrotic syndrome in the J-RBR

In the cohort of primary glomerular diseases (except $\operatorname{IgA}$ nephropathy) as classified based on the pathogenesis, membranous nephropathy (MN) was predominant in 2009, followed by minor glomerular abnormalities, while minor glomerular abnormalities were the most common diagnosis in 2010, followed by MN (Table 8). 


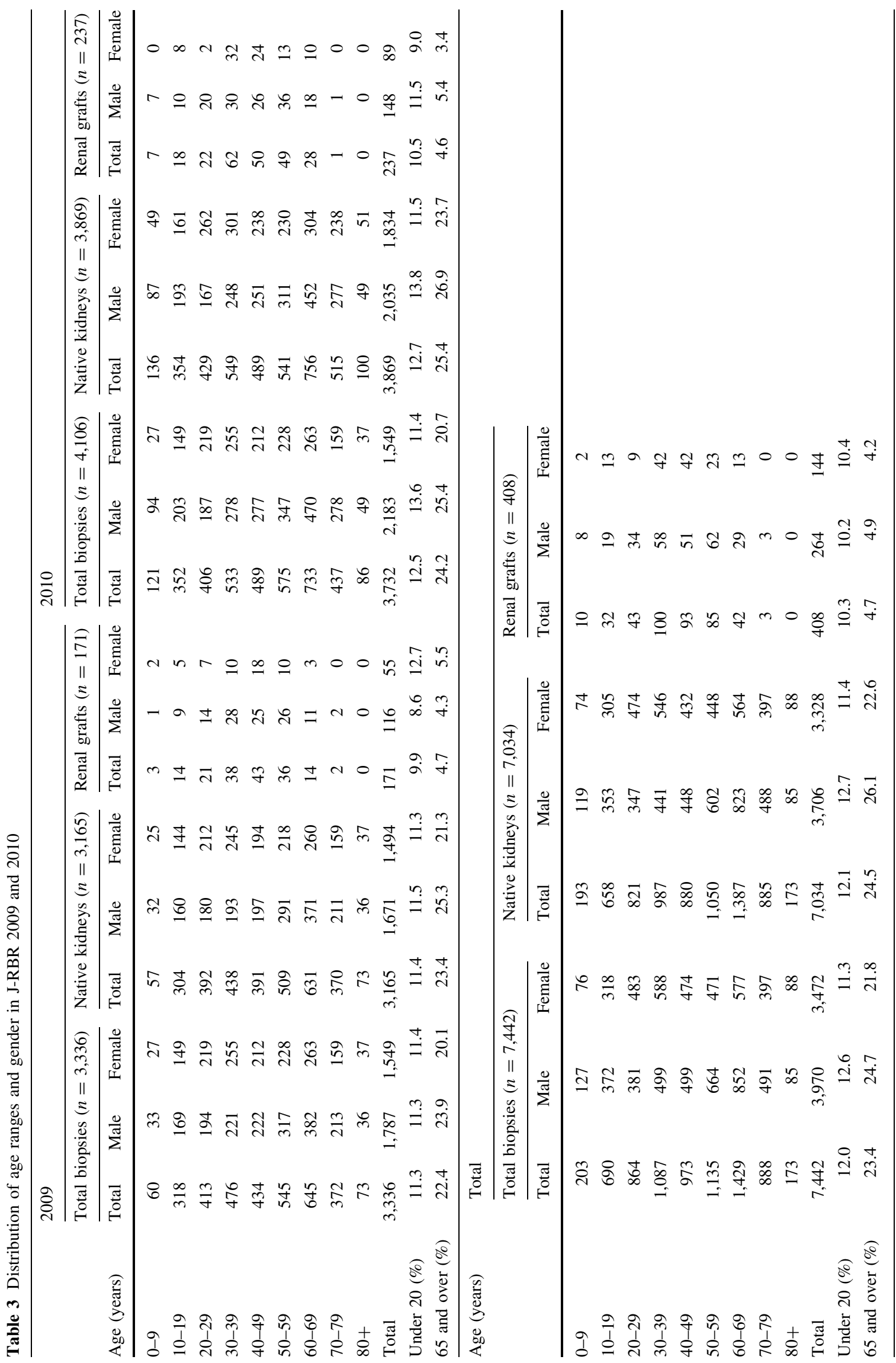


Table 4 The frequency of classification of clinical diagnoses in J-RBR 2009 and 2010

\begin{tabular}{|c|c|c|c|c|c|c|c|c|c|}
\hline \multirow[t]{3}{*}{ Classification } & \multicolumn{3}{|l|}{2009} & \multicolumn{3}{|l|}{2010} & \multicolumn{3}{|l|}{ Total } \\
\hline & \multicolumn{2}{|c|}{$\begin{array}{l}\text { Total } \\
\text { biopsies } \\
(n=3,336)\end{array}$} & \multirow{2}{*}{$\begin{array}{l}\text { Native kidneys } \\
(n=3,165) \\
\%^{\mathrm{a}}\end{array}$} & \multicolumn{2}{|c|}{$\begin{array}{l}\text { Total } \\
\text { biopsies } \\
(n=4,106)\end{array}$} & \multirow{2}{*}{$\begin{array}{l}\text { Native kidneys } \\
(n=3,869) \\
\%^{\mathrm{a}}\end{array}$} & \multicolumn{2}{|c|}{$\begin{array}{l}\text { Total } \\
\text { biopsies } \\
(n=7,442)\end{array}$} & \multirow{2}{*}{$\begin{array}{l}\text { Native kidneys } \\
(n=7,034) \\
\%^{\mathrm{a}}\end{array}$} \\
\hline & $n$ & $\%$ & & $n$ & $\%$ & & $n$ & $\%$ & \\
\hline Chronic nephritic syndrome & 1,759 & 52.7 & 55.4 & 1,944 & 47.3 & 50.0 & 3,703 & 49.8 & 52.5 \\
\hline Nephrotic syndrome & 711 & 21.3 & 22.4 & 1,044 & 25.4 & 27.0 & 1,755 & 23.6 & 24.9 \\
\hline $\begin{array}{l}\text { Rapidly progressive nephritic } \\
\text { syndrome }\end{array}$ & 200 & 6.0 & 6.3 & 292 & 7.1 & 7.5 & 492 & 6.6 & 7.0 \\
\hline Renal transplantation & 160 & 4.8 & - & 227 & 5.5 & - & 387 & 5.2 & - \\
\hline $\begin{array}{l}\text { Renal disorder with collagen } \\
\text { disease or vasculitis }\end{array}$ & 116 & 3.5 & 3.7 & 144 & 3.5 & 3.7 & 260 & 3.5 & 3.7 \\
\hline Recurrent or persistent hematuria & 97 & 2.9 & 3.0 & 111 & 2.7 & 2.9 & 208 & 2.8 & 2.9 \\
\hline $\begin{array}{l}\text { Renal disorder with metabolic } \\
\text { disease }\end{array}$ & 63 & 1.9 & 2.0 & 61 & 1.5 & 1.6 & 124 & 1.7 & 1.8 \\
\hline Acute nephritic syndrome & 54 & 1.6 & 1.6 & 58 & 1.4 & 1.5 & 112 & 1.5 & 1.6 \\
\hline Hypertensive nephropathy & 39 & 1.2 & 1.2 & 54 & 1.3 & 1.4 & 93 & 1.3 & 1.3 \\
\hline Acute renal failure & 36 & 1.1 & 1.1 & 35 & 0.9 & 0.9 & 71 & 1.0 & 1.0 \\
\hline Drug-induced nephropathy & 13 & 0.4 & 0.4 & 26 & 0.6 & 0.6 & 39 & 0.5 & 0.5 \\
\hline Inherited renal disease & 6 & 0.2 & 0.2 & 15 & 0.4 & 0.4 & 21 & 0.3 & 0.3 \\
\hline HUS/TTP & - & - & - & 3 & 0.1 & 0.1 & 3 & 0.0 & 0.0 \\
\hline Others & 82 & 2.5 & 2.6 & 92 & 2.2 & 2.4 & 174 & 2.4 & 2.5 \\
\hline Total & 3,336 & 100.0 & 100.0 & 4,106 & 100.0 & 100.0 & 7,442 & 100.0 & 100.0 \\
\hline
\end{tabular}

"Patients classified as either "Renal graft" or "Renal transplantation" in other categories were also excluded

In the patients with nephrotic syndrome as classified by the clinical diagnosis, primary glomerular disease other than IgAN was the predominant diagnosis in both 2009 and 2010, followed by diabetic nephropathy, which was the same order as in 2007 and 2008 (Table 9). Among the patients with primary glomerular diseases (except IgA nephropathy) who had nephrotic syndrome, MN was dominant, followed by minor glomerular abnormalities, viz., minimal change nephrotic syndrome (MCNS), focal segmental glomerulosclerosis (FSGS), and membranoproliferative glomerulonephritis (MPGN) (types I and III) in 2009. In 2010, minor glomerular abnormalities were the leading diagnosis, followed by MN, FSGS, and MPGN (types I and III) (Table 10).

Clinical diagnosis of membranous nephropathy, minor glomerular abnormalities, and focal segmental glomerulosclerosis in patients with primary glomerular diseases (except IgA nephropathy) in the J-RBR

A subanalysis of the subjects with a clinical diagnosis of $\mathrm{MN}$, minor glomerular abnormalities, and FSGS who had primary glomerular diseases (except IgA nephropathy) was also performed, since these were the most common forms of such diseases. Nephrotic syndrome was the most common clinical diagnosis in cases with primary $\mathrm{MN}$ and primary minor glomerular abnormalities (MCNS) (Tables 11, 12), whereas chronic nephritic syndrome and nephrotic syndrome were the most common in cases with primary FSGS in 2009 and 2010, respectively (Table 13).

\section{Subanalysis of cases of IgA nephropathy in the J-RBR}

The profile, distribution of age ranges, classification of the clinical diagnosis, and the pathological diagnosis of IgAN, the most common glomerulonephritis reported in the J-RBR, were further analyzed (Tables 14, 15, 16, 17, 18, S2, S3). The average age of the overall subjects was in the fourth decade. There were no differences in the proportion of patients based on gender, but the age was significantly higher in males than in females in 2009 (Table 14). In terms of the distribution of age ranges, the peak distribution was in the twenties individually in both genders and in the overall cases in 2009, while it was in the thirties in both genders and overall in 2010, as well as in the combined data from 2009 and 2010 (Table 15). Patients younger than 20 years of age comprised $14.4 \%$ of the cases and those 65 years and over comprised $7.9 \%$ of the cases in the combined data from 2009 and 2010 (Table 15). The majority of the clinical and pathological diagnoses were chronic nephritic syndrome (Table 16) and mesangial proliferative glomerulonephritis (Table 17), respectively, 
Table 5 The age distribution of classification of clinical diagnoses in native kidneys in J-RBR 2009 and 2010

\begin{tabular}{|c|c|c|c|c|c|c|c|c|c|}
\hline \multirow[t]{2}{*}{ Classification } & \multicolumn{3}{|l|}{2009} & \multicolumn{3}{|l|}{2010} & \multicolumn{3}{|l|}{ Total } \\
\hline & Male & Female & Total & Male & Female & Total & Male & Female & Total \\
\hline $\begin{array}{l}\text { Chronic nephritic } \\
\text { syndrome }\end{array}$ & $44.4 \pm 18.8$ & $41.2 \pm 17.8$ & $42.8 \pm 18.4$ & $43.5 \pm 19.3$ & $41.0 \pm 18.2$ & $42.2 \pm 18.8$ & $43.9 \pm 19.1$ & $41.0 \pm 18.0$ & $42.5 \pm 18.6$ \\
\hline $\begin{array}{l}\text { Nephrotic } \\
\text { syndrome }\end{array}$ & $52.6 \pm 21.6$ & $54.7 \pm 21.1$ & $53.5 \pm 21.4$ & $49.5 \pm 23.4$ & $50.9 \pm 22.6$ & $50.1 \pm 23.0$ & $50.8 \pm 22.7$ & $52.5 \pm 22.0$ & $51.5 \pm 22.4$ \\
\hline $\begin{array}{l}\text { Rapidly } \\
\text { progressive } \\
\text { nephritic } \\
\text { syndrome }\end{array}$ & $64.5 \pm 13.0$ & $61.2 \pm 17.4$ & $63.0 \pm 15.1$ & $65.4 \pm 11.5$ & $65.3 \pm 15.3$ & $65.4 \pm 13.3$ & $65.1 \pm 12.1$ & $63.6 \pm 16.3$ & $64.4 \pm 14.1$ \\
\hline $\begin{array}{l}\text { Renal disorder with } \\
\text { collagen disease } \\
\text { or vasculitis }\end{array}$ & $48.0 \pm 21.5$ & $46.2 \pm 20.1$ & $46.7 \pm 20.4$ & $54.3 \pm 19.5$ & $46.3 \pm 19.6$ & $48.7 \pm 19.9$ & $51.6 \pm 20.5$ & $46.2 \pm 19.8$ & $47.8 \pm 20.1$ \\
\hline $\begin{array}{l}\text { Recurrent or } \\
\text { persistent } \\
\text { hematuria }\end{array}$ & $33.4 \pm 17.4$ & $33.8 \pm 16.9$ & $33.6 \pm 17.0$ & $49.5 \pm 19.0$ & $38.0 \pm 17.1$ & $42.6 \pm 18.6$ & $41.8 \pm 19.9$ & $36.1 \pm 17.0$ & $38.4 \pm 18.4$ \\
\hline $\begin{array}{l}\text { Renal disorder with } \\
\text { metabolic disease }\end{array}$ & $56.9 \pm 12.3$ & $57.9 \pm 8.9$ & $57.2 \pm 11.5$ & $56.8 \pm 14.8$ & $54.8 \pm 14.1$ & $56.2 \pm 14.5$ & $56.9 \pm 13.5$ & $56.2 \pm 11.9$ & $56.7 \pm 13.0$ \\
\hline $\begin{array}{l}\text { Acute nephritic } \\
\text { syndrome }\end{array}$ & $42.8 \pm 19.2$ & $36.0 \pm 22.5$ & $39.9 \pm 20.7$ & $49.6 \pm 17.5$ & $46.6 \pm 21.1$ & $48.1 \pm 19.3$ & $46.1 \pm 18.5$ & $42.0 \pm 22.1$ & $44.2 \pm 20.3$ \\
\hline $\begin{array}{l}\text { Hypertensive } \\
\text { nephropathy }\end{array}$ & $56.2 \pm 13.5$ & $51.0 \pm 15.3$ & $55.2 \pm 13.8$ & $54.5 \pm 15.9$ & $54.7 \pm 17.0$ & $54.6 \pm 16.0$ & $55.3 \pm 14.8$ & $53.3 \pm 16.1$ & $54.8 \pm 15.1$ \\
\hline Acute renal failure & $56.0 \pm 19.3$ & $56.4 \pm 26.2$ & $56.1 \pm 21.2$ & $55.2 \pm 17.6$ & $58.0 \pm 20.6$ & $56.0 \pm 18.2$ & $55.6 \pm 18.3$ & $57.1 \pm 23.1$ & $56.0 \pm 19.7$ \\
\hline $\begin{array}{l}\text { Drug-induced } \\
\text { nephropathy }\end{array}$ & $53.6 \pm 11.9$ & $35.2 \pm 21.6$ & $45.1 \pm 18.9$ & $47.3 \pm 20.0$ & $60.4 \pm 17.6$ & $51.5 \pm 19.9$ & $49.1 \pm 18.0$ & $49.6 \pm 22.7$ & $49.3 \pm 19.5$ \\
\hline $\begin{array}{l}\text { Inherited renal } \\
\text { disease }\end{array}$ & $25.0 \pm 23.8$ & $40.7 \pm 24.1$ & $32.8 \pm 23.1$ & $15.0 \pm 17.1$ & $24.3 \pm 25.3$ & $19.3 \pm 21.1$ & $17.7 \pm 18.5$ & $29.2 \pm 24.9$ & $23.2 \pm 22.0$ \\
\hline HUS/TTP & - & - & - & 10,69 & 49 & $42.6 \pm 30.0$ & 10,69 & 49 & $42.6 \pm 30.0$ \\
\hline Others & $50.6 \pm 18.2$ & $48.4 \pm 19.5$ & $49.6 \pm 18.7$ & $48.6 \pm 20.9$ & $53.3 \pm 18.1$ & $50.5 \pm 19.8$ & $49.4 \pm 19.6$ & $50.9 \pm 18.9$ & $50.0 \pm 19.2$ \\
\hline Total & $48.4 \pm 20.0$ & $45.5 \pm 20.0$ & $47.0 \pm 20.1$ & $48.2 \pm 21.0$ & $46.0 \pm 20.5$ & $47.1 \pm 20.8$ & $48.3 \pm 20.6$ & $45.8 \pm 20.3$ & $47.1 \pm 20.5$ \\
\hline
\end{tabular}

in 2009 and 2010. The distribution of chronic kidney disease (CKD) stages, degree of proteinuria and clinical parameters in $\mathrm{IgAN}$ were analyzed in the combined data from 2009 and 2010 (Tables 18, S2, S3).

With regard to the stages of CKD in patients with IgAN, stage 2 was predominant in the combined data from 2009 and 2010 (Table 18) and in both genders (Tables S2 and S3). The degree of proteinuria in the 24-h urine or spot urine samples increased with the progression of CKD stages in the combined data from 2009 and 2010 (Table 18) and in both genders (Tables S2 and S3). The systolic and diastolic blood pressure also increased with the progression of the CKD stage (Tables 18, S2, S3). Overall, $37.0 \%$ of IgAN cases were being treated with antihypertensive agents and $4.6 \%$ had diabetes mellitus (Table 18).

Cases in the J-KDR not reported in the J-RBR

In cases in the J-KDR not reported in the J-RBR, a clinical diagnosis of chronic nephritic syndrome was predominant in 2009, followed by hypertensive nephropathy, and a clinical diagnosis of renal disorder with metabolic disease (diabetic nephropathy) was predominant in 2010, followed by nephrotic syndrome (Table 19). Polycystic kidney disease was detected in 2010 as a result of the secondary research studies performed on the basis of the J-KDR as described in the "Subjects and methods" section.

Secondary and longitudinal research by the J-RBR/JKDR

Five of the secondary and longitudinal research studies, viz., the JNSCS, J-IDCS, J-IGACS, JRPGN-CS, and JDNCS, were started in 2009, and the J-PKD was started in 2010 in association with the J-RBR/J-KDR.

\section{Discussion and comments}

In 2009, the J-KDR started to register clinically-diagnosed cases without renal biopsies, in addition to cases with renal biopsies included in the J-RBR, which had been started in 2007. More than $80 \%$ of the registered cases were in the J-RBR in 2009 and 2010, and thus the detailed data from the J-RBR and the clinical diagnosis alone for the J-KDR are described in this report. 
Table 6 The frequency of pathological diagnoses as classified by pathogenesis in J-RBR 2009 and 2010

\begin{tabular}{|c|c|c|c|c|c|c|c|c|c|}
\hline \multirow[t]{3}{*}{ Classification } & \multicolumn{3}{|l|}{2009} & \multicolumn{3}{|l|}{2010} & \multicolumn{3}{|l|}{ Total } \\
\hline & \multicolumn{2}{|c|}{$\begin{array}{l}\text { Total } \\
\text { biopsies } \\
(n=3,336)\end{array}$} & \multirow{2}{*}{$\begin{array}{l}\text { Native kidneys } \\
(n=3,165) \\
\%^{\mathrm{a}}\end{array}$} & \multicolumn{2}{|c|}{$\begin{array}{l}\text { Total } \\
\text { biopsies } \\
(n=4,106)\end{array}$} & \multirow{2}{*}{$\begin{array}{l}\text { Native kidneys } \\
(n=3,869)\end{array}$} & \multicolumn{2}{|c|}{$\begin{array}{l}\text { Total } \\
\text { biopsies } \\
(n=7,442)\end{array}$} & \multirow{2}{*}{$\begin{array}{l}\text { Native kidneys } \\
(n=7,034) \\
\%^{\mathrm{a}}\end{array}$} \\
\hline & $n$ & $\%$ & & $n$ & $\%$ & & $n$ & $\%$ & \\
\hline IgA nephropathy & 1,003 & 30.1 & 31.6 & 1,177 & 28.7 & 30.4 & 2,180 & 29.3 & 31.0 \\
\hline $\begin{array}{r}\text { Primary glomerular disease } \\
\text { (except IgA nephropathy) }\end{array}$ & 862 & 25.8 & 27.2 & 1,090 & 26.5 & 28.1 & 1,952 & 26.2 & 27.7 \\
\hline Diabetic nephropathy & 184 & 5.5 & 5.8 & 192 & 4.7 & 5.0 & 376 & 5.1 & 5.3 \\
\hline Renal graft & 161 & 4.8 & - & 235 & 5.7 & - & 396 & 5.3 & - \\
\hline Lupus nephritis & 137 & 4.1 & 4.3 & 220 & 5.4 & 5.7 & 357 & 4.8 & 5.1 \\
\hline MPO-ANCA positive nephritis & 129 & 3.9 & 4.1 & 191 & 4.7 & 4.9 & 320 & 4.3 & 4.5 \\
\hline Hypertensive nephrosclerosis & 123 & 3.7 & 3.9 & 157 & 3.8 & 4.1 & 280 & 3.8 & 4.0 \\
\hline Purpura nephritis & 64 & 1.9 & 2.0 & 108 & 2.6 & 2.8 & 172 & 2.3 & 2.4 \\
\hline Amyloid nephropathy & 45 & 1.3 & 1.4 & 58 & 1.4 & 1.5 & 103 & 1.4 & 1.5 \\
\hline Infection-related nephropathy & 27 & 0.8 & 0.9 & 31 & 0.8 & 0.8 & 58 & 0.8 & 0.8 \\
\hline Thin basement membrane disease & 26 & 0.8 & 0.8 & 39 & 1.0 & 1.0 & 65 & 0.9 & 0.9 \\
\hline PR3-ANCA positive nephritis & 13 & 0.4 & 0.4 & 11 & 0.3 & 0.3 & 24 & 0.3 & 0.3 \\
\hline Alport syndrome & 10 & 0.3 & 0.3 & 16 & 0.4 & 0.4 & 26 & 0.3 & 0.4 \\
\hline Thrombotic microangiopathy & 9 & 0.3 & 0.3 & 8 & 0.2 & 0.2 & 17 & 0.2 & 0.2 \\
\hline Anti-GBM antibody-type nephritis & 8 & 0.2 & 0.3 & 16 & 0.4 & 0.4 & 24 & 0.3 & 0.3 \\
\hline Others & 535 & 16.0 & 16.7 & 557 & 13.6 & 13.6 & 1,092 & 14.7 & 15.4 \\
\hline Total & 3,336 & 100.0 & 100.0 & 4,106 & 100.0 & 100.0 & 7,442 & 100.0 & 100.0 \\
\hline
\end{tabular}

$M P O$ myeloperoxidase, $A N C A$ anti-neutrophil cytoplasmic antibody, $P R 3$ proteinase 3, GBM glomerular basement membrane

a Patients classified as either "Renal graft" or "Renal transplantation" in other categories were also excluded

The rates of primary glomerular disease (except IgAN) combined with that of IgAN in native renal biopsies were $59.3 \%, 56.5 \%, 58.8 \%$, and $58.5 \%$ in $2007,2008,2009$, and 2010 in the J-RBR. A recent report from a single center in Japan gave the rates as $77.8 \%$ and $75.9 \%$ between 1979 and 2008 and between 2004 and 2008, respectively [5]. In the present report for the J-RBR, the peak distribution of age was in the sixties in the combined data for 2009 and 2010. The difference in the rates of primary glomerular disease including IgAN may have been due to the higher mean ages of native biopsy cases in the J-RBR compared to the single center in this period (mean age, 46.7 vs. 40.8 years; age of the peak number, sixties vs. twenties), because the incidence of secondary glomerular disease increases in elderly patients, as reported previously [5].

IgAN is still the most frequently diagnosed disease in native kidney biopsies in Japan $(33.0 \%, 30.2 \%, 31.6 \%$, and $30.4 \%$ of cases in 2007, 2008, 2009, and 2010 in the J-RBR) [1, 4-6] similar to other Asian countries [7, 8] and some European countries $[9,10]$. The peak distribution of age ranges was the twenties in 2009 and thirties in 2010. In patients with IgAN, the majority $(68.1 \%)$ of renal biopsies were performed in CKD stages G1 and G2, with median proteinuria less than $1 \mathrm{~g}$ per day (Table 18), suggesting that there was a relatively early diagnosis of this biopsyproven disease.

In the present clinical data, the degree of proteinuria increased with the progression of the CKD stage, and was more than $1 \mathrm{~g}$ per day for the median value in patients with CKD stages G4 and G5 (Tables 18, S1, S2). Previously, the best single predictor for renal deterioration was severe proteinuria on urine dipstick testing $(\geq 100 \mathrm{mg} / \mathrm{dL})$, followed by hypoalbuminemia, mild hematuria, serum total protein levels, diastolic blood pressure, and histological grade, in a cohort study with 10 years follow-up from 1995 in Japan, the cohort of which exhibited a younger median age (27.7 years) and a peak distribution of age ranges in the teens $[11,12]$. A recent report suggested that IgAN with nephrotic syndrome had a worse renal outcome compared to $\operatorname{IgAN}$ with non-nephrotic syndrome unless partial or complete remission was achieved [13]. Further studies are necessary to elucidate the risk factors or predictors for renal deterioration in IgAN in the present era utilizing the J-RBR, possibly as part of a new secondary clinical study.

MN was the most common histopathology in terms of primary glomerular disease other than IgAN in 2007 
Table 7 The frequency of pathological diagnoses as classified by histopathology in J-RBR 2009 and 2010

\begin{tabular}{|c|c|c|c|c|c|c|c|c|c|}
\hline \multirow[t]{3}{*}{ Classification } & \multicolumn{3}{|l|}{2009} & \multicolumn{3}{|l|}{2010} & \multicolumn{3}{|l|}{ Total } \\
\hline & \multicolumn{2}{|c|}{$\begin{array}{l}\text { Total } \\
\text { biopsies } \\
(n=3,336)\end{array}$} & \multirow{2}{*}{$\begin{array}{l}\text { Native kidneys } \\
(n=3,165) \\
\%^{\mathrm{a}}\end{array}$} & \multicolumn{2}{|c|}{$\begin{array}{l}\text { Total } \\
\text { biopsies } \\
(n=4,106)\end{array}$} & \multirow{2}{*}{$\begin{array}{l}\text { Native kidneys } \\
(n=3,869) \\
\%^{\mathrm{a}}\end{array}$} & \multicolumn{2}{|c|}{$\begin{array}{l}\text { Total } \\
\text { biopsies } \\
(n=7,442)\end{array}$} & \multirow{2}{*}{$\begin{array}{l}\text { Native kidneys } \\
(n=7,034) \\
\%^{\mathrm{a}}\end{array}$} \\
\hline & $n$ & $\%$ & & $n$ & $\%$ & & $n$ & $\%$ & \\
\hline $\begin{array}{l}\text { Mesangial proliferative } \\
\text { glomerulonephritis }\end{array}$ & 1,346 & 40.3 & 42.5 & 1,388 & 33.8 & 35.8 & 2,734 & 36.7 & 38.8 \\
\hline Membranous nephropathy & 333 & 10.0 & 10.5 & 418 & 10.2 & 10.8 & 751 & 10.1 & 10.7 \\
\hline Minor glomerular abnormality & 293 & 8.8 & 9.2 & 559 & 13.6 & 14.4 & 852 & 11.4 & 12.1 \\
\hline $\begin{array}{l}\text { Crescentic and necrotizing } \\
\text { glomerulonephritis }\end{array}$ & 180 & 5.4 & 5.7 & 262 & 6.4 & 6.8 & 442 & 5.9 & 6.3 \\
\hline Focal segmental glomerulosclerosis & 167 & 5.0 & 5.2 & 211 & 5.1 & 5.4 & 378 & 5.1 & 5.3 \\
\hline Nephrosclerosis & 163 & 4.9 & 5.2 & 208 & 5.1 & 5.4 & 371 & 5.0 & 5.3 \\
\hline Renal graft & 151 & 4.5 & - & 227 & 5.5 & - & 378 & 5.1 & - \\
\hline $\begin{array}{l}\text { Membranoproliferative } \\
\text { glomerulonephritis (types I and III) }\end{array}$ & 85 & 2.5 & 2.7 & 97 & 2.4 & 2.5 & 182 & 2.4 & 2.6 \\
\hline Chronic interstitial nephritis & 71 & 2.1 & 2.1 & 61 & 1.5 & 1.6 & 132 & 1.7 & 1.8 \\
\hline Sclerosing glomerulonephritis & 63 & 1.9 & 2.0 & 44 & 1.1 & 1.1 & 107 & 1.4 & 1.5 \\
\hline $\begin{array}{l}\text { Endocapillary proliferative } \\
\text { glomerulonephritis }\end{array}$ & 61 & 1.8 & 1.9 & 67 & 1.6 & 1.7 & 128 & 1.7 & 1.8 \\
\hline Acute interstitial nephritis & 45 & 1.3 & 1.4 & 62 & 1.5 & 1.6 & 107 & 1.4 & 1.5 \\
\hline Acute tubular necrosis & 9 & 0.3 & 0.3 & 10 & 0.2 & 0.2 & 19 & 0.3 & 0.2 \\
\hline Dense deposit disease & 3 & 0.1 & 0.1 & 5 & 0.1 & 0.1 & 8 & 0.1 & 0.1 \\
\hline Others & 366 & 11.0 & 11.3 & 487 & 11.9 & 12.5 & 853 & 11.5 & 12.0 \\
\hline Total & 3,336 & 100.0 & 100.0 & 4,106 & 100.0 & 100.0 & 7,442 & 100.0 & 100.0 \\
\hline
\end{tabular}

a Patients classified as either "Renal graft" or "Renal transplantation" in other categories were also excluded

Table 8 The frequency of pathological diagnoses as classified by histopathology in primary glomerular disease except IgA nephropathy in native kidneys in J-RBR 2009 and 2010

\begin{tabular}{|c|c|c|c|c|c|c|}
\hline \multirow[t]{2}{*}{ Classification } & \multicolumn{2}{|c|}{2009} & \multicolumn{2}{|l|}{2010} & \multicolumn{2}{|l|}{ Total } \\
\hline & $n$ & $\%$ & $n$ & $\%$ & $n$ & $\%$ \\
\hline Membranous nephropathy & 259 & 30.1 & 330 & 30.3 & 589 & 30.2 \\
\hline Minor glomerular abnormalities & 216 & 25.1 & 408 & 37.5 & 624 & 32.0 \\
\hline Mesangial proliferative glomerulonephritis & 167 & 19.4 & 86 & 7.9 & 253 & 13.0 \\
\hline Focal segmental glomerulosclerosis & 113 & 13.1 & 149 & 13.7 & 262 & 13.4 \\
\hline Membranoproliferative glomerulonephritis (types I and III) & 48 & 5.6 & 51 & 4.7 & 99 & 5.1 \\
\hline Crescentic and necrotizing glomerulonephritis & 19 & 2.2 & 18 & 1.7 & 37 & 1.9 \\
\hline $\begin{array}{l}\text { Endocapillary proliferative } \\
\text { glomerulonephritis }\end{array}$ & 8 & 0.9 & 24 & 2.2 & 32 & 1.6 \\
\hline Chronic interstitial nephritis & 7 & 0.8 & 3 & 0.3 & 10 & 0.5 \\
\hline Sclerosing glomerulonephritis & 7 & 0.8 & 3 & 0.3 & 10 & 0.5 \\
\hline Nephrosclerosis & 5 & 0.6 & 7 & 0.6 & 12 & 0.6 \\
\hline Acute interstitial nephritis & 1 & 0.1 & 0 & - & 1 & 0.1 \\
\hline Acute tubular necrosis & 0 & - & 1 & 0.1 & 1 & 0.1 \\
\hline Others & 11 & 1.3 & 9 & 0.8 & 20 & 1.0 \\
\hline Total & 861 & 100.0 & 1,089 & 100.0 & 1,950 & 100.0 \\
\hline
\end{tabular}


Table 9 The frequency of pathological diagnoses as classified by pathogenesis in nephrotic syndrome in native kidneys in J-RBR 2009 and 2010

\begin{tabular}{|c|c|c|c|c|c|c|}
\hline \multirow[t]{2}{*}{ Classification } & \multicolumn{2}{|c|}{2009} & \multicolumn{2}{|l|}{2010} & \multicolumn{2}{|l|}{ Total } \\
\hline & $n$ & $\%$ & $n$ & $\%$ & $n$ & $\%$ \\
\hline Primary glomerular disease (except $\operatorname{Ig}$ A nephropathy) & 442 & 62.3 & 696 & 66.7 & 1,138 & 64.9 \\
\hline Diabetic nephropathy & 85 & 12.0 & 78 & 7.5 & 163 & 9.3 \\
\hline IgA nephropathy & 30 & 4.2 & 36 & 3.5 & 66 & 3.8 \\
\hline Lupus nephritis & 30 & 4.2 & 58 & 5.6 & 88 & 5.0 \\
\hline Amyloid nephropathy & 27 & 3.8 & 41 & 3.9 & 68 & 3.9 \\
\hline Infection-related nephropathy & 6 & 0.8 & 7 & 0.7 & 13 & 0.7 \\
\hline Hypertensive nephrosclerosis & 6 & 0.8 & 10 & 0.9 & 16 & 0.9 \\
\hline Purpura nephritis & 4 & 0.6 & 8 & 0.8 & 12 & 0.7 \\
\hline Alport syndrome & 3 & 0.4 & 0 & - & 3 & 0.2 \\
\hline Thrombotic microangiopathy & 1 & 0.1 & 1 & 0.1 & 2 & 0.1 \\
\hline PR3-ANCA positive nephritis & 1 & 0.1 & 0 & - & 1 & 0.1 \\
\hline MPO-ANCA positive nephritis & 1 & 0.1 & 2 & 0.2 & 3 & 0.2 \\
\hline Others & 74 & 10.4 & 106 & 10.2 & 180 & 10.3 \\
\hline Total & 710 & 100.0 & 1,043 & 100.0 & 1,753 & 100.0 \\
\hline
\end{tabular}

$M P O$ myeloperoxidase, $A N C A$ anti-neutrophil cytoplasmic antibody, $P R 3$ proteinase 3

Table 10 The frequency of pathological diagnoses as classified by histopathology in primary glomerular disease except IgA nephropathy in nephrotic syndrome in native kidneys in J-RBR 2009 and 2010

\begin{tabular}{|c|c|c|c|c|c|c|}
\hline \multirow[t]{2}{*}{ Classification } & \multicolumn{2}{|c|}{2009} & \multicolumn{2}{|c|}{2010} & \multicolumn{2}{|l|}{ Total } \\
\hline & $n$ & $\%$ & $n$ & $\%$ & $n$ & $\%$ \\
\hline Membranous nephropathy & 178 & 40.3 & 227 & 32.6 & 405 & 35.6 \\
\hline Minor glomerular abnormalities & 172 & 38.9 & 348 & 50.0 & 520 & 45.7 \\
\hline Focal segmental glomerulosclerosis & 47 & 10.6 & 82 & 11.8 & 129 & 11.3 \\
\hline Membranoproliferative glomerulonephritis (types I and III) & 25 & 5.7 & 18 & 2.6 & 43 & 3.8 \\
\hline Mesangial proliferative glomerulonephritis & 11 & 2.5 & 13 & 1.9 & 24 & 2.1 \\
\hline Crescentic and necrotizing glomerulonephritis & 2 & 0.5 & 2 & 0.3 & 4 & 0.4 \\
\hline Sclerosing glomerulonephritis & 2 & 0.5 & 0 & - & 2 & 0.2 \\
\hline Endocapillary proliferative glomerulonephritis & 1 & 0.2 & 5 & 0.7 & 6 & 0.5 \\
\hline Others & 4 & 0.9 & 1 & 0.1 & 5 & 0.4 \\
\hline Total & 442 & 100.0 & 696 & 100.0 & 1,138 & 100.0 \\
\hline
\end{tabular}

(31.4\%), $2008(25.7 \%)$, and 2009 (30.1\%) in the J-RBR and was also the most common type in primary nephrotic syndrome in $2007(44.0 \%)$ and $2009(40.3 \%)$ in the J-RBR. MN was also the most common primary cause of nephrotic syndrome in a northern European Caucasian population, with a biopsy rate of 4.5 per million population per year [14]. A total of $68.7 \%$ and $68.8 \%$ of primary $\mathrm{MN}$ cases exhibited nephrotic syndrome as the clinical diagnosis at the time of renal biopsy in 2009 and 2010 in the J-RBR. Yokoyama et al. recently reported in their clinical data analysis of 501 cases collected from the combined data of the J-RBR from 2007 to 2010 that nearly half of primary $\mathrm{MN}(49.1 \%)$ cases showed a daily proteinuria of $3.5 \mathrm{~g}$ or higher [15]. The renal survival rate was $60 \%$ at 20 years after diagnosis in patients with primary $\mathrm{MN}$, and the renal survival rate in patients on steroid therapy was significantly higher in patients on supportive therapy alone in Japan [16], while spontaneous remission was reported to be common (32\%) in patients with primary MN with nephrotic syndrome in Spain [17], even in patients exhibiting chronic renal impairment [18]. Whether treatment with renin-angiotensin blockers or immunoglobulins other than steroids has a favorable effect on the renal prognosis of primary $\mathrm{MN}$ should be elucidated in future clinical studies.

The minor glomerular abnormalities in primary nephrotic syndrome, which correspond to MCNS, was the most common histopathology reported in 2008 (44.1\%) and $2010(50.0 \%)$ in the J-RBR. Since MCNS develops in patients at younger ages $[5,15]$ while primary $\mathrm{MN}$ develops in a relatively elderly population $[15,16]$, the frequency of these diseases may depend on the distribution of 
Table 11 The frequency of clinical diagnoses in membranous nephropathy in primary glomerular disease except IgA nephropathy in native kidneys in J-RBR 2009 and 2010

\begin{tabular}{|c|c|c|c|c|c|c|}
\hline \multirow[t]{2}{*}{ Classification } & \multicolumn{2}{|c|}{2009} & \multicolumn{2}{|c|}{2010} & \multicolumn{2}{|c|}{ Total } \\
\hline & $n$ & $\%$ & $n$ & $\%$ & $n$ & $\%$ \\
\hline Nephrotic syndrome & 178 & 68.7 & 227 & 68.8 & 405 & 68.8 \\
\hline Chronic nephritic syndrome & 74 & 28.6 & 93 & 28.2 & 167 & 28.4 \\
\hline Recurrent or persistent hematuria & 3 & 1.2 & 3 & 0.9 & 6 & 1.0 \\
\hline Renal disorder with collagen disease or vasculitis & 1 & 0.4 & 1 & 0.3 & 2 & 0.3 \\
\hline Hypertensive nephropathy & 1 & 0.4 & 0 & - & 1 & 0.2 \\
\hline Rapidly progressive nephritic syndrome & 0 & - & 1 & 0.3 & 1 & 0.2 \\
\hline Renal disorder with metabolic disease & 0 & - & 1 & 0.3 & 1 & 0.2 \\
\hline Acute nephritic syndrome & 0 & - & 1 & 0.3 & 1 & 0.2 \\
\hline Acute renal failure & 0 & - & 1 & 0.3 & 1 & 0.2 \\
\hline Others & 2 & 0.8 & 2 & 0.6 & 4 & 0.7 \\
\hline Total & 259 & 100.0 & 330 & 100.0 & 589 & 100.0 \\
\hline
\end{tabular}

Table 12 The frequency of clinical diagnoses in minor glomerular abnormalities in primary glomerular disease except IgA nephropathy in native kidneys in J-RBR 2009 and 2010

\begin{tabular}{|c|c|c|c|c|c|c|}
\hline \multirow[t]{2}{*}{ Classification } & \multicolumn{2}{|c|}{2009} & \multicolumn{2}{|c|}{2010} & \multicolumn{2}{|c|}{ Total } \\
\hline & $n$ & $\%$ & $n$ & $\%$ & $n$ & $\%$ \\
\hline Nephrotic syndrome & 172 & 79.6 & 348 & 85.3 & 520 & 83.3 \\
\hline Chronic nephritic syndrome & 35 & 16.2 & 50 & 12.3 & 85 & 13.6 \\
\hline Recurrent or persistent hematuria & 5 & 2.3 & 5 & 1.2 & 10 & 1.6 \\
\hline Acute renal failure & 1 & 0.5 & 0 & - & 1 & 0.2 \\
\hline Rapidly progressive nephritic syndrome & 1 & 0.5 & 1 & 0.2 & 2 & 0.3 \\
\hline Acute nephritic syndrome & 1 & 0.5 & 1 & 0.2 & 2 & 0.3 \\
\hline Hypertensive nephropathy & 0 & - & 1 & 0.2 & 1 & 0.2 \\
\hline Others & 1 & 0.5 & 2 & 0.5 & 3 & 0.5 \\
\hline Total & 216 & 100.0 & 408 & 100.0 & 624 & 100.0 \\
\hline
\end{tabular}

the age ranges of patients registered in each year. Indeed, the rate of native biopsies of subjects younger than 20 years of age slightly increased from $11.4 \%$ in 2009 to $12.7 \%$ in 2010 (Table 3) and the mean age of patients with nephrotic syndrome slightly decreased from 53.5 years in 2009 to 50.1 years in 2010 (Table 5) in the J-RBR.

The average age of rapidly progressive nephritic syndrome was the highest (64.4 years) in the age distribution in the classification of clinical diagnosis in the J-RBR (Table 5). Elderly subjects (65 years and over) comprised nearly $25 \%$ of cases, and very elderly subjects (80 years and over) comprised $2.5 \%$ of the cases in the combined data for 2009 and 2010 in the J-RBR. It has been reported that there were statistically significant differences in the renal disease spectrum between elderly and younger subjects $[19,20]$. The frequency of rapidly progressive nephritic syndrome in the clinical diagnosis dramatically increased from $4.0 \%$ in the younger group (20-64 years) to $19.6 \%$ in the very elderly in the combined data from 2007 to November 2011 in the J-RBR [20]. A nationwide survey of rapidly progressive glomerulonephritis (RPGN) was conducted between 1989 and 2007 in Japan, and showed that $64.0 \%$ of patients had pauci-immune-type RPGN, including $42.0 \%$ renal-limited vasculitis, $19.4 \%$ microscopic polyangiitis, and $2.6 \%$ Wegener's granulomatosis (currently granulomatosis with polyangiitis) [21]. Since the frequency of myeloperoxidase-anti-neutrophil cytoplasmic antibody (MPO-ANCA)-positive nephritis has increased recently [22], a further subanalysis of rapidly progressive nephritic syndrome in the J-RBR should be performed to validate the recently published Japanese guidelines for RPGN [23].

Five new secondary research studies of the J-KDR were started in 2009, viz., the J-NSCS, J-IDCS, J-IGACS, J-RPGNCS, and J-DNCS, and the J-PKD was started in 2010. The J-RBR and J-KDR initiated two more clinical 
Table 13 The frequency of clinical diagnoses in focal segmental glomerulosclerosis in primary glomerular disease except IgA nephropathy in native kidneys in J-RBR 2009 and 2010

\begin{tabular}{|c|c|c|c|c|c|c|}
\hline \multirow[t]{2}{*}{ Classification } & \multicolumn{2}{|c|}{2009} & \multicolumn{2}{|c|}{2010} & \multicolumn{2}{|c|}{ Total } \\
\hline & $n$ & $\%$ & $n$ & $\%$ & $n$ & $\%$ \\
\hline Chronic nephritic syndrome & 62 & 54.9 & 55 & 36.9 & 117 & 44.7 \\
\hline Nephrotic syndrome & 47 & 41.6 & 82 & 55.0 & 129 & 49.2 \\
\hline Rapidly progressive nephritic syndrome & 1 & 0.9 & 1 & 0.7 & 2 & 0.8 \\
\hline Renal disorder with metabolic disease & 1 & 0.9 & 3 & 2.0 & 4 & 1.5 \\
\hline Recurrent or persistent hematuria & 1 & 0.9 & 1 & 0.7 & 2 & 0.8 \\
\hline Hypertensive nephropathy & 0 & - & 2 & 1.3 & 2 & 0.8 \\
\hline Acute nephritic syndrome & 0 & - & 1 & 0.7 & 1 & 0.4 \\
\hline Inherited renal disease & 0 & - & 1 & 0.7 & 1 & 0.4 \\
\hline Others & 1 & 0.9 & 3 & 2.0 & 4 & 1.5 \\
\hline Total & 113 & 100.0 & 149 & 100.0 & 262 & 100.0 \\
\hline
\end{tabular}

Table 14 The profile of IgA nephropathy in native kidneys in J-RBR 2009 and 2010

\begin{tabular}{llll}
\hline IgA nephropathy & 2009 & 2010 & Total \\
\hline Total native kidney biopsies $(n)$ & 1,001 & 1,176 & 2,177 \\
Average age (years) & $38.1 \pm 17.2$ & $39.3 \pm 17.0$ & $38.7 \pm 17.1$ \\
Median age (years) & $35(24-52)$ & $38(26-53)$ & $37(25-52)$ \\
Male, $n(\%)$ & $498(49.8 \%)^{\mathrm{a}}$ & $585(49.7 \%)$ & $1,083(49.7 \%)$ \\
Average age (years) & $39.5 \pm 18.2^{\mathrm{b}}$ & $40.5 \pm 18.4^{\mathrm{b}}$ & $40.0 \pm 18.3^{\mathrm{b}}$ \\
Median age (years) & $38(24-55)^{\mathrm{b}}$ & $39(25-56)$ & $38(24-56)^{\mathrm{b}}$ \\
Female, $n(\%)$ & $503(50.2 \%)^{\mathrm{a}}$ & $591(50.3 \%)$ & $1,094(50.3 \%)$ \\
Average age & $36.6 \pm 15.9^{\mathrm{b}}$ & $38.1 \pm 15.4^{\mathrm{b}}$ & $37.5 \pm 15.7^{\mathrm{b}}$ \\
Median age & $34(24-49)^{\mathrm{b}}$ & $37(26-49)$ & $36(25-49)^{\mathrm{b}}$ \\
\hline
\end{tabular}

${ }^{a}$ Ratio indicates percentage of each gender in each biopsy category

b $P<0.05$ compared to other gender

Table 15 Distribution of age ranges and gender in IgA nephropathy in J-RBR in 2009 and 2010

\begin{tabular}{|c|c|c|c|c|c|c|c|c|c|}
\hline \multirow[t]{2}{*}{ Age (years) } & \multicolumn{3}{|l|}{2009} & \multicolumn{3}{|l|}{2010} & \multicolumn{3}{|l|}{ Total } \\
\hline & Male & Female & Total & Male & Female & Total & Male & Female & Total \\
\hline $0-9$ & 11 & 5 & 16 & 12 & 9 & 21 & 23 & 14 & 37 \\
\hline 10-19 & 73 & 68 & 141 & 80 & 55 & 135 & 153 & 123 & 276 \\
\hline $20-29$ & 91 & 116 & 207 & 91 & 127 & 218 & 182 & 243 & 425 \\
\hline $30-39$ & 87 & 115 & 202 & 113 & 153 & 266 & 200 & 268 & 468 \\
\hline $40-49$ & 65 & 81 & 146 & 94 & 106 & 200 & 159 & 187 & 346 \\
\hline $50-59$ & 87 & 62 & 149 & 84 & 75 & 159 & 171 & 137 & 308 \\
\hline $60-69$ & 62 & 45 & 107 & 82 & 48 & 130 & 144 & 93 & 237 \\
\hline 70-79 & 19 & 9 & 28 & 20 & 18 & 38 & 39 & 27 & 66 \\
\hline $80+$ & 3 & 2 & 5 & 9 & 0 & 9 & 12 & 2 & 14 \\
\hline Total & 498 & 503 & 1,001 & 585 & 591 & 1,176 & 1,083 & 1,094 & 2,177 \\
\hline Under $20(\%)$ & 16.9 & 14.5 & 15.7 & 15.7 & 10.8 & 13.3 & 16.3 & 12.5 & 14.4 \\
\hline 65 and over (\%) & 9.4 & 5.2 & 7.3 & 11.5 & 5.4 & 8.4 & 10.5 & 5.3 & 7.9 \\
\hline
\end{tabular}


Table 16 The frequency of classification of clinical diagnoses in IgA nephropathy in native kidneys in J-RBR 2009 and 2010

\begin{tabular}{|c|c|c|c|c|c|c|}
\hline \multirow[t]{2}{*}{ Clinical diagnosis } & \multicolumn{2}{|l|}{2009} & \multicolumn{2}{|l|}{2010} & \multicolumn{2}{|l|}{ Total } \\
\hline & $n$ & $\%$ & $n$ & $\%$ & $n$ & $\%$ \\
\hline Chronic nephritic syndrome & 886 & 88.5 & 1,064 & 90.5 & 1,950 & 89.6 \\
\hline Recurrent or persistent hematuria & 49 & 4.9 & 40 & 3.4 & 89 & 4.1 \\
\hline Nephrotic syndrome & 30 & 3.0 & 36 & 3.1 & 66 & 3.0 \\
\hline Rapidly progressive nephritic syndrome & 14 & 1.4 & 20 & 1.7 & 34 & 1.6 \\
\hline Acute nephritic syndrome & 8 & 0.8 & 9 & 0.8 & 17 & 0.8 \\
\hline Renal disorder with collagen disease or vasculitis & 4 & 0.4 & 1 & 0.1 & 5 & 0.2 \\
\hline Acute renal failure & 2 & 0.2 & 2 & 0.2 & 4 & 0.2 \\
\hline Drug-induced nephropathy & 2 & 0.2 & 1 & 0.1 & 3 & 0.1 \\
\hline Renal disorder with metabolic disease & 1 & 0.1 & 0 & - & 1 & 0.0 \\
\hline Hypertensive nephropathy & 0 & - & 1 & 0.1 & 1 & 0.0 \\
\hline Others & 5 & 0.5 & 2 & 0.2 & 7 & 0.3 \\
\hline Total & 1,001 & 100.0 & 1,176 & 100.0 & 2,177 & 100.0 \\
\hline
\end{tabular}

Table 17 The frequency of pathological diagnoses as classified by histopathology in IgAN in native kidneys in J-RBR 2009 and 2010

\begin{tabular}{|c|c|c|c|c|c|c|}
\hline \multirow[t]{2}{*}{ Pathological diagnosis by histopathology } & \multicolumn{2}{|l|}{2009} & \multicolumn{2}{|l|}{2010} & \multicolumn{2}{|l|}{ Total } \\
\hline & $n$ & $\%$ & $n$ & $\%$ & $n$ & $\%$ \\
\hline Mesangial proliferative glomerulonephritis & 937 & 93.6 & 1,111 & 94.5 & 2,048 & 94.1 \\
\hline Endocapillary proliferative glomerulonephritis & 12 & 1.2 & 2 & 0.2 & 14 & 0.6 \\
\hline Minor glomerular abnormalities & 12 & 1.2 & 15 & 1.3 & 27 & 1.2 \\
\hline Focal segmental glomerulosclerosis & 9 & 0.9 & 6 & 0.5 & 15 & 0.7 \\
\hline Crescentic and necrotizing glomerulonephritis & 8 & 0.8 & 10 & 0.9 & 18 & 0.8 \\
\hline Nephrosclerosis & 6 & 0.6 & 4 & 0.3 & 10 & 0.5 \\
\hline Membranous nephropathy & 4 & 0.4 & 2 & 0.2 & 6 & 0.3 \\
\hline Membranoproliferative glomerulonephritis (types I and III) & 4 & 0.4 & 5 & 0.4 & 9 & 0.4 \\
\hline Sclerosing glomerulonephritis & 3 & 0.3 & 2 & 0.2 & 5 & 0.2 \\
\hline Chronic interstitial nephritis & 1 & 0.1 & 2 & 0.2 & 3 & 0.1 \\
\hline Acute interstitial nephritis & 0 & - & 1 & 0.1 & 1 & 0.0 \\
\hline Others & 5 & 0.5 & 16 & 1.4 & 21 & 1.0 \\
\hline Total & 1,001 & 100.0 & 1,176 & 100.0 & 2,177 & 100.0 \\
\hline
\end{tabular}

research studies (J-RBR201001 and J-KDR201001) being performed by members of the JSN who had already participated in the registry and who registered cases under the precise regulations presented on the website of the JSN in 2011.

With regard to estimating the number of yearly native renal biopsies in Japan, the Research Group on Progressive Renal Disease from the Ministry of Health, Labor and Welfare of Japan recently reported by a questionnaire method that it was between 18,000 and 21,000 in 2010. The J-RBR may cover nearly one fourth to one fifth of the number of yearly native renal biopsies in Japan in 2010 . Since $128,057,352$ people resided in Japan in 2010, the estimated rate of renal biopsy was 140.6 to 164.0 per million population. This rate was higher than that in Romania [24], Spain [25], the Czech Republic [10], Denmark [26], and Scotland [27], was similar to that in France [28], and was lower than that in USA, Finland [29], and Australia [30].

There are some limitations in the J-RBR and J-KDR. The J-RBR records three diagnoses for each case, viz., the clinical diagnosis, diagnosis based on the pathogenesis, and the diagnosis based on a histopathological examination, so there may be still some inconsistency in the case records. The terms hypertensive nephropathy, hypertensive nephrosclerosis, nephrosclerosis, and diabetic nephropathy may need to be defined more precisely to improve the accuracy of the report by the J-RBR. The incidence of renal biopsy 


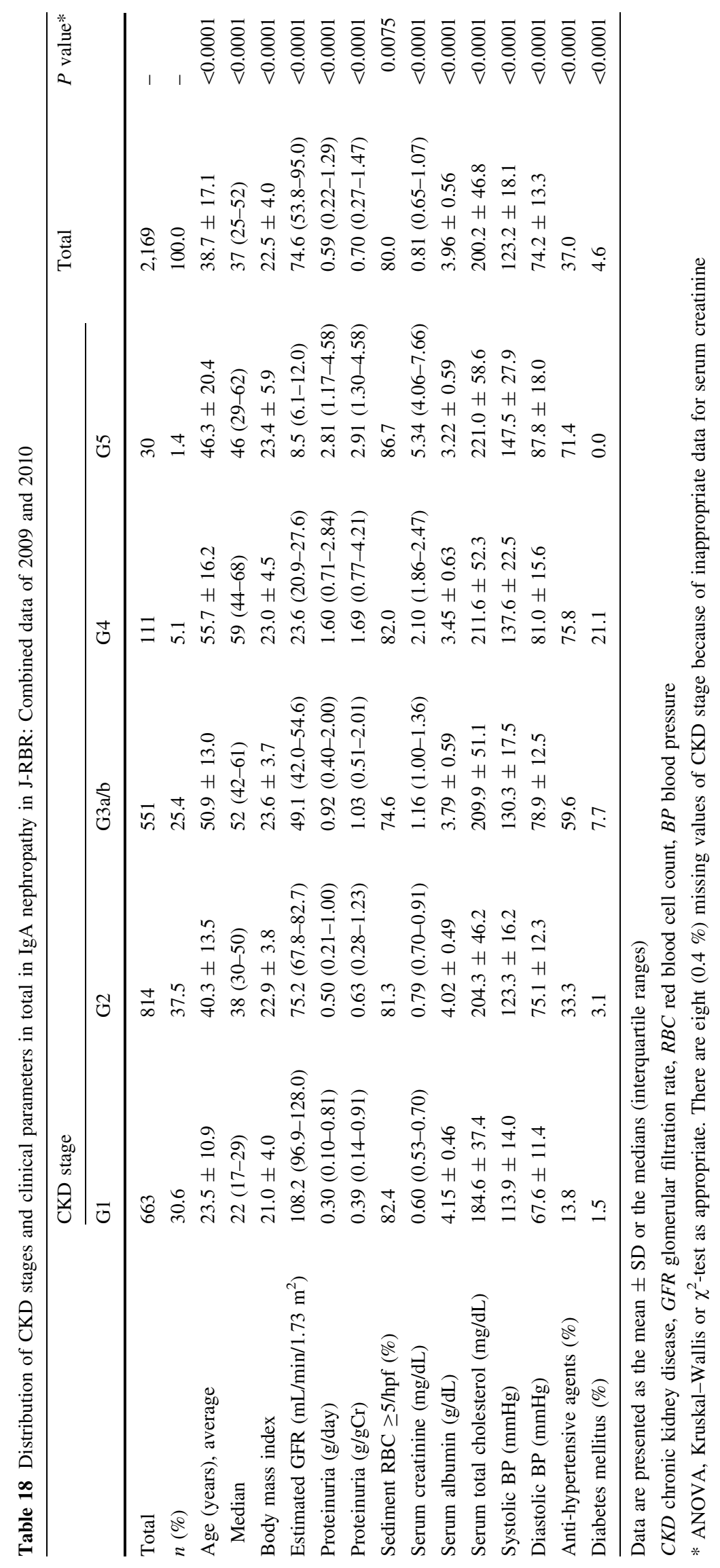


Table 19 The frequency of classification of clinical diagnoses in other 680 cases than J-RBR in J-KDR 2009 and 2010

\begin{tabular}{|c|c|c|c|c|c|c|}
\hline \multirow[t]{2}{*}{ Classification } & \multicolumn{2}{|c|}{$\begin{array}{l}\text { Other cases } \\
2009 \\
(n=680)\end{array}$} & \multicolumn{2}{|c|}{$\begin{array}{l}\text { Other cases } \\
2010 \\
(n=575)\end{array}$} & \multicolumn{2}{|c|}{$\begin{array}{l}\text { Total } \\
(n=1,255)\end{array}$} \\
\hline & $n$ & $\%$ & $n$ & $\%$ & $n$ & $\%$ \\
\hline $\begin{array}{l}\text { Chronic nephritic } \\
\text { syndrome }\end{array}$ & 165 & 24.3 & 72 & 12.5 & 237 & 18.9 \\
\hline $\begin{array}{l}\text { Hypertensive } \\
\text { nephropathy }\end{array}$ & 142 & 20.9 & 43 & 7.5 & 185 & 14.7 \\
\hline $\begin{array}{l}\text { Renal disorder with } \\
\text { metabolic disease }\end{array}$ & 106 & 15.6 & 177 & 30.8 & 283 & 22.5 \\
\hline Nephrotic syndrome & 86 & 12.6 & 118 & 20.5 & 204 & 16.3 \\
\hline $\begin{array}{l}\text { Renal disorder with } \\
\text { collagen disease or } \\
\text { vasculitis }\end{array}$ & 24 & 3.5 & 7 & 1.2 & 31 & 2. \\
\hline $\begin{array}{l}\text { Rapidly progressive } \\
\text { nephritic syndrome }\end{array}$ & 21 & 3.1 & 18 & 3.1 & 39 & 3.1 \\
\hline Inherited renal disease & 18 & 2.6 & 3 & 0.5 & 21 & 1.7 \\
\hline Acute renal failure & 9 & 1.3 & 10 & 1.7 & 19 & 1.5 \\
\hline $\begin{array}{l}\text { Recurrent or persistent } \\
\text { hematuria }\end{array}$ & 8 & 1.2 & 0 & - & 8 & 0.6 \\
\hline $\begin{array}{l}\text { Acute nephritic } \\
\text { syndrome }\end{array}$ & 5 & 0.7 & 4 & 0.7 & 9 & 0.7 \\
\hline $\begin{array}{l}\text { Drug-induced } \\
\text { nephropathy }\end{array}$ & 5 & 0.7 & 0 & - & 5 & 0.4 \\
\hline Renal transplantation & 2 & 0.3 & 9 & 1.6 & 11 & 0.9 \\
\hline $\begin{array}{l}\text { Polycystic kidney } \\
\text { disease }\end{array}$ & - & - & 82 & 14.3 & 82 & 6.5 \\
\hline Others & 89 & 13.1 & 32 & 5.6 & 121 & 9.6 \\
\hline Total & 680 & 100.0 & 575 & 100.0 & 1,255 & 100.0 \\
\hline
\end{tabular}

and the incidence of biopsy-proven renal diseases such as IgAN and primary glomerular disease (except IgAN) could be surveyed in major renal centers in Japan in terms of the epidemiological aspects to work out appropriate countermeasures. In this aspect, the incidence of pediatric IgAN was reported to be 4.5 cases/year per 100,000 children under 15 years of age from 1983 to 1999 in Yonago City, Japan [31], although center variations in the country in terms of the incidence, indications and diagnosis of adult native renal biopsy have been reported [27].

Finally, a committee report of J-KDR including J-RBR in 2009, 2010 and their total was conducted. The J-RBR exhibited the majority of the registry system to elucidate yearly demographic data of renal biopsies in Japan, and J-KDR was utilized to promote advanced clinical research in the field of nephrology in our country.

Acknowledgments The authors greatly acknowledge the help and assistance of many colleagues in centers and affiliate hospitals with collection of data for the J-RBR/J-KDR. We also sincerely thank Ms. M. Irie of the UNIN-INDICE and Ms. Y. Saito of the JSN for supporting the registration system and Ms. K. Fukuda of the JSN for submitting the manuscript. This study was supported by the committee grant from the Japanese Society of Nephrology and by a grantin-aid from the Research Group on Progressive Renal Disease from the Ministry of Health, Labor and Welfare, Japan.

Conflict of interest T. Saito was supported by Novartis Pharma Co. and Kyowa-Kirin Co. Other authors declare no competing interests.

\section{Appendix}

The following facilities and investigators participated in the project for the J-RBR and J-KDR:

Hokkaido District

- Asahikawa Medical University Hospital (Division of Cardiology, Nephrology, Pulmonology and Neurology, Department of Internal Medicine), Naoyuki Hasebe, Naoki Nakagawa, Junko Chinda

- National Hospital Organization Hokkaido Medical Center (Department of Nephrology), Tetsuya Kawata, Tsuyoshi Yamamura

- Hokkaido University Graduate School of Medicine (Department of Medicine II), Saori Nishio, Sekiya Shibazaki, Yasunobu Ishikawa, Daigo Nakazawa

- Hokkaido University Graduate School of Medicine (Department of Pediatrics), Satoshi Sasaki, Yasuyuki Sato, Takeshi Yamazaki, Takayuki Okamoto

- KKR Sapporo Medical Center (Department of Pathology), Akira Suzuki

Tohoku District

- Iwate Prefectural Central Hospital (Department of Nephrology), Jun Soma, Izaya Nakaya, Mayumi Yahata

- Fukushima Medical University School of Medicine (Department of Nephrology, Hypertension, Diabetology, Endocrinology, and Metabolism), Tsuyoshi Watanabe, Koichi Asahi, Hiroaki Satoh

- Sendai Shakaihoken Hospital (Department of Nephrology), Toshinobu Sato, Asako Fujimori, Hisako Sugai, Mitsuhiro Sato

- Tohoku University Hospital and affiliated hospitals (Internal Medicine), Keisuke Nakayama, Takashi Nakamichi

- Yamagata University School of Medicine (Department of Cardiology, Pulmonology, and Nephrology), Tsuneo Konta, Kazunobu Ichikawa, Ami Ikeda, Kazuko Suzuki

- Yamagata University School of Medicine (Department of Pediatrics), Akira Matsunaga 
Kanto District

- National Hospital Organization Chiba-East National Hospital (Clinical Research Center), Hiroshi Kitamura, Takashi Kenmochi, Motonobu Nishimura, Hideaki Kurayama (Department of Urology), Koichi Kamura

- Dokkyo Medical University Koshigaya Hospital (Department of Nephrology), Tetsuro Takeda

- Dokkyo Medical University School of Medicine (Department of Cardiology and Nephrology), Toshihiko Ishimitsu

- Gunma University Graduate School of Medicine (Department of Science and Clinical Medicine), Yoshihisa Nojima, Keijyu Hiromura

- Jichi Medical University (Division of Nephrology), Eiji Kusano

- The Jikei University School of Medicine (Division of Kidney and Hypertension), Tatsuo Hosoya, Tetsuya Kawamura, Yasunori Utsunomiya, Yoichi Miyazaki

- The Jikei University School of Medicine, Katsushika Medical Center (Division of Kidney and Hypertension), Masato Ikeda, Keita Hirano, Akihiro Shimizu

- The Jikei University School of Medicine, Daisan Hospital (Division of Kidney and Hypertension), Kazushige Hanaoka, Kentaro Koike, Haruko Suetsugu, Mai Tanaka

- The Jikei University Kashiwa Hospital (Division of Kidney and Hypertension), Makoto Ogura, Akihiko Hamaguchi, Yukio Maruyama, Seiji Kobayashi

- Juntendo University Faculty of Medicine (Division of Nephrology, Department of Internal Medicine), Yasuhiko Tomino, Isao Ohsawa, Chieko Hamada, Satoshi Horikoshi

- Kawaguchi Municipal Medical Center (Division of Nephrology), Takeo Ishii

- Kyorin University School of Medicine (Department of Urology), Kikuo Nutahara

- Mito Saiseikai General Hospital (Division of Nephrology), Itaru Ebihara, Chihiro Satho

- Nippon Medical School (Division of Nephrology, Department of Internal Medicine), Yasuhiko Iino, Tomohiro Kaneko, Akiko Mii, Akio Hirama

- Nihon University School of Medicine (Division of Nephrology, Hypertension and Endocrinology), Koichi Matsumoto

- Saitama Medical University, Faculty of Medicine (Department of Nephrology), Hirokazu Okada, Hiromichi Suzuki, Tsutomu Inoue

- Saitama Medical University, Saitama Medical Center (Department of Nephrology and Hypertension), Tetsuya Mitarai, Juko Asakura, Sinpei Okazaki, Hajime Hasegawa
- Showa University School of Medicine (Division of Nephrology), Aki Kuroki

- Showa University Fujigaoka Hospital (Division of Nephrology), Yoshihiko Inoue

- St. Marianna University School of Medicine (Division of Nephrology and Hypertension, Department of Internal Medicine), Kenjiro Kimura, Takashi Yasuda, Sayuri Shirai

- Tokai University School of Medicine (Division of Nephrology, Endocrinology and Metabolism), Masayuki Endoh, Hisae Tanaka

- Teikyo University School of Medicine (Department of Internal Medicine), Shunya Uchida

- Teikyo University School of Medicine (Department of Urology), Shigeo Horie, Satoru Muto

- Tokyo Medical University Ibaraki Medical Center (Department of Nephrology), Masaki Kobayashi, Kouichi Hirayama, Homare Shimohata

- Tokyo Metropolitan Children's Medical Center (Department of Nephrology), Hiroshi Hataya

- Tokyo Women's Medical University (Department of Pediatric Nephrology), Motoshi Hattori, Kiyonobu Ishizuka, Noriko Sugawara

- Tokyo Women's Medical University (The Forth Department of Medicine), Kosaku Nitta, Keiko Uchida, Takahito Moriyama

- University of Tokyo Hospital (Department of Hemodialysis \& Apheresis), Norio Hanafusa

- University of Tokyo (Department of Nephrology and Endocrinology), Toshiro Fujita, Masaomi Nangaku, Takehiko Wada

- University of Tsukuba, Faculty of Medicine (Department of Nephrology), Kunihiro Yamagata, Joichi Usui, Tetsuya Kawamura

- Yokohama City University Graduate School of Medicine and School of Medicine (Department of Medical Science and Cardiorenal Medicine), Satoshi Umemura, Masato Oosawa

- Yokohama City University Medical Center, Nobuhito Hirawa, Keisuke Yatsu, Yuichiro Yamamoto, Sanae Saka

Koushinetsu District

- Niigata University Graduate School of Medical and Dental Sciences (Division of Clinical Nephrology and Rheumatology), Ichiei Narita, Shin Goto, Yumi Itoh, Naofumi Imai

- Shinshu University School of Medicine (Division of Nephrology), Yuji Kamijo, Wataru Tsukada, Koji Hashimoto

- University of Yamanashi Hospital (Third Department of Internal Medicine), Fumihiko Furuya, Daiichiro Akiyama, Kazuya Takahashi, Ayako Okamura 
Hokuriku District

- National Hospital Organization Kanazawa Medical Center (Department of Nephrology and Rheumatology), Mitsuhiro Yoshimura, Takuyuki Ise

- Kanazawa Medical University School of Medicine (Division of Nephrology), Hitoshi Yokoyama, Hiroshi Okuyama, Keiji Fujimoto, Junko Imura

- Kanazawa Medical University (Division of Diabetes \& Endocrinology), Daisuke Koya, Yuka Kurosima, Miho Ohba

- Kanazawa University Hospital (Division of Nephrology), Takashi Wada, Kiyoki Kitagawa, Kengo Furuichi

- Katou Hospital, Yasuhiro Katou, Hiroyuki Yamauchi, Yasunori Iwata, Kazutoshi Yamada

- Moriyama Koshino Clinic, Yoshitaka Koshino

- Pubulic Central Hospital of Matto-Ishikawa, Kazuya Takasawa, Chikako Takaeda

- Sugita Genpaku Memorial Obama Municipal Hospital, Haruyoshi Yoshida, Takayasu Horiguchi

- Toyama Prefectural Central Hospital (Department of Internal Medicine), Junya Yamahana, Masahiko Kawabata

- University of Fukui, Faculty of Medical Sciences (Division of Nephrology, Department of General Medicine), Masayuki Iwano, Hideki Kimura, Naoki Takahashi, Kenji Kasuno

- University of Toyama (Second Department of Internal Medicine), Fumihiro Tomoda

Tokai District

- Aichi Children's Health and Medical Center (Department of Pediatric Nephrology), Osamu Uemura, Takuhito Nagai, Satoshi Yamakawa

- Aichi Medical University School of Medicine (Division of Nephrology and Rheumatology), Naoto Miura, Hirokazu Imai

- Fujinomiya City General Hospital, Masanori Sakakima, Kazuto Kitajima, Taichi Sato, Yutaro Kawakatsu

- Fujita Health University School of Medicine (Department of Nephrology), Yukio Yuzawa, Satoshi Sugiyama

- Hamamatsu University School of Medicine, University Hospital (Internal Medicine1, Division of Nephrology), Yoshihide Fujigaki, Masafumi Ono, Takamasa Iwakura

- Japanese Red Cross Nagoya Daini Hospital (Kidney Center), Kunio Morozumi, Asami Takeda, Yasuhiro Otsuka

- Nagoya City University Graduate School of Medical Sciences (Department of Cardio-Renal Medicine and Hypertension), Genjiro Kimura, Michio Fukuda, Toshiyuki Miura, Atsuhiro Yoshida

- Nagoya Kyoritsu Hospital (Department of Internal Medicine), Hirotake Kasuga
- Nagoya University Graduate School of Medicine (Department of Nephrology), Seiichi Matsuo, Shoichi Maruyama, Waichi Sato, Yoshinari Yasuda

- Shizuoka General Hospital (Department of Nephrology), Noriko Mori, Satoshi Tanaka

Kinki District

- Hyogo Prefectural Nisihinomiya Hospital (Department of Pathology), Kazumasa Oka

- Ikeda City Hospital (Division of Nephrology), Nobuyuki Kajiwara

- Kitano Hospital, The Tazukekofukai Medical Research Institute (Division of Nephrology and Dialysis), Eri Muso, Kazuo Tosikoshi, Tomomi Endo, Yukako Iwasaki

- Kobe University Graduate School of Medicine (Division of Nephrology and Kidney Center), Shinichi Nishi, Shunske Goto

- National Hospital Organization Kyoto Medical Center (Division of Nephrology), Koichi Seta, Kensei Yahata

- Kyoto Prefectural University School of Medicine (Division of Nephrology, Department of Medicine), Yasukiyo Mori, Keiichi Tamagaki

- Kyoto University Graduate School of Medicine (Department of Nephrology), Motoko Yanagita, Tatsuo Tsukamoto, Noriyuki Iehara, Takeshi Matsubara

- Kyoto University Graduate School of Medicine (Department of Medicine and Clinical Science), Masashi Mukoyama, Hideki Yokoi, Tomoko Kawanishi, Akira Ishii

- Mie University Graduate School of Medicine Hospital (Department of Nephrology and Hemodialysis Center), Shinsuke Nomura, Mika Fujimoto, Eiji Ishikawa, Tomohiro Murata

- Nara Medical University (First Department of Internal Medicine), Yoshihiko Saito, Kenichi Samejima

- National Cerebral and Cardiovascular Center (Division of Hypertension and Nephrology), Satoko Nakamura

- Osaka City University Graduate School of Medicine (Department of Nephrology), Eiji Ishimura, Ikue Kobayashi, Mitsuru Ichii, Yoshiteru Ohno

- Osaka City General Hospital (Division of Nephrology and Hypertension), Masahito Imanishi, Takashi Morikawa, Chizuko Kitabayashi, Yoshio Konishi

- Osaka General Medical Center (Department of Kidney Disease and Hypertension), Yoshiharu Tsubakihara, Tatsuya Shoji

- Osaka Medical Center and Research Institute for Maternal and Child Health (Department of Pediatric Nephrology and Metabolism), Kenichi Satomura

- Osaka Red Cross Hospital (Department of Nephrology), Akira Sugawara, Masao Koshikawa, Yoshihisa Ogawa, Tomoko Kawanishi 
- Osaka University Graduate School of Medicine (Department of Geriatric Medicine and Nephrology), Yoshitaka Isaka, Yasuyuki Nagasawa, Ryohei Yamamoto

- Saiseikai Shiga Hospital (Division of Nephrology), Toshiki Nishio

- Shiga University of Medical Science (Department of Medicine), Shinichi Araki

- Shirasagi Hospital (Kidney Center), Shigeichi Shoji, Kenjiro Yamakawa, Senji Okuno

- Toyonaka Municipal Hospital (Division of Nephrology), Megumu Fukunaga

- Wakayama Medical University (Department of Pediatrics), Norishige Yoshikawa, Koichi Nakanishi, Yuko Shima

- Wakayama Medical University (Division of Nephrology, Department of Internal Medicine), Takashi Shigematsu, Masaki Ohya

- Yokkaichi Social Insurance Hospital (Division of Nephrology and Blood Purification), Yasuhide Mizutani, Hitoshi Kodera, Masato Miyake

Chugoku District

- Kawasaki Medical School (Department of Nephrology and Hypertension), Naoki Kashihara,Tamaki Sasaki, Sohachi Fujimoto

- Kurashiki Central Hospital (Division of Nephrology), Kenichiro Asano, Masaru Kinomura

- Hiroshima University Hospital (Department of Nephrology), Takao Masaki, Sigehiro Doi, Yukio Yokoyama, Ayumu Nakashima

- Mizushima Kyodo Hospital (Department of Internal Medicine), Nobuyoshi Sugiyama, Yuichirou Inaba, Kan Yamasaki, Kouji Ozeki

- Okayama Saiseikai General Hospital (Department of Nephrology), Makoto Hiramatsu, Keisuke Maruyama, Noriya Momoki

- Okayama University Graduate School of Medicine, Dentistry, and Pharmaceutical Sciences (Department of Medicine and Clinical Science), Hiroshi Morinaga, Tatsuyuki Inoue, Keiichi Takiue

- Saiseikai Yamaguchi General Hospital (Department of Internal Medicine), Tsuyoshi Imai

- Shimane University Faculty of Medicine (Division of Nephrology), Takafumi Ito

- Tottori University Hospital (Division of Pediatrics and Perinatology), Shinichi Okada, Yasuo Kawaba, Koichi Kitamoto

Shikoku District

- Kagawa University, Faculty of Medicine (Department of CardioRenal and Cerebrovascular Medicine \& Departmnet of Clinical Pathology), Masakazu Kohno, Kumiko Moriwaki, Taiga Hara, Yoshio Kushida
- Kochi University, Kochi Medical School (Department of Endocrinology, Metabolism and Nephrology), Yoshio Terada, Toru Kagawa, Taro Horino, Yoshiko Shimamura

- The University of Tokushima Graduate School of Medicine (Department of Pediatrics, Institute of Health Bioscience), Shoji Kagami, Maki Urushihara, Shuji Kondo

- The University of Tokushima, Graduate School of Medicine (Department of Nephrology), Toshio Doi, Hideharu Abe, Kojiro Nagai

Kyushu District

- Fukuoka University School of Medicine (Division of Nephrology \& Rheumatology, Departments of Internal Medicine), Takao Saito, Yoshie Sasatomi, Satoru Ogahara, Satoshi Hisano

- Japanese Red Cross Fukuoka Hospital (Department of Pediatrics), Ken Hatae, Maiko Hinokiyama, Hiroyo Maruyama

- Japanese Red Cross Fukuoka Hospital (Nephrology and Dialysis Center), Hideki Hirakata, Koji Mitsuiki

- Kumamoto University Graduate School of Medical Sciences (Department of Nephrology), Kenichiro Kitamura, Yushi Nakayama

- Jinseikai Clinic Hikarinomori, Yukimasa Kohda

- Kurume University School of Medicine (Division of Nephrology, Department Medicine), Seiya Okuda, Daisuke Wakasugi, Kiyomi Koike

- Kyushu University Graduate School of Medical Sciences (Department of Medicine and Clinical Science), Kazuhiko Tsuruya, Shunsuke Yamada, Akihiro Tsuchimoto

- Kyushu University Graduate School of Medical Sciences (Department of Environmental Medicine), Yutaka Kiyohara, Toshiharu Ninomiya, Masaharu Nagata

- Miyazaki Prefectural Miyazaki Hospital (Division of Nephrology), Naoko Yokota-Ikeda, Shigehiro Uezono, Keiko Kodama

- Nagasaki University Hospital (Department of Pathology), Takashi Taguchi

- Nagasaki University Hospital (Second Department of Internal Medicine), Tomoya Nishino, Hideyuki Arai, Yoko Obata, Tadashi Uramatsu

- National Fukuoka Higashi Medical Center (Kidney Unit), Ritsuko Katafuchi

- Oitaken Kouseiren Tsurumi Hospital (Division of Nephrology), Ryokichi Yasumori

- Saga University, Faculty of Medicine (Department of Cardiovascular and Renal Medicine), Toru Sanai

- St. Mary's Hospital, Harumichi Higashi

- University of Miyazaki Hospital (First Department of Internal Medicine), Shouichi Fujimoto, Yuji Sato, Masao Kikuchi 
- University of Occupational and Environmental Health (Second Department of Internal Medicine), Masahito Tamura, Tetsu Miyamoto

- Ryukyu University Graduate School of Medicine (Department of Cardiology, Nephrology and Neurology), Yusuke Ohya, Kentaro Kohagura, Kunitoshi Iseki, Yusuke Ohya

\section{References}

1. Sugiyama H, Yokoyama H, Sato H, Saito T, Kohda Y, Nishi S, et al. Japan Renal Biopsy Registry: the first nationwide, webbased, and prospective registry system of renal biopsies in Japan. Clin Exp Nephrol. 2011;15:493-503.

2. Churg J, Bernstein J, Glassock RJ, editors. Renal disease, classification and atlas of glomerular disease. 2nd ed. Tokyo: IgakuShoin; 1995.

3. Matsuo S, Imai E, Horio M, Yasuda Y, Tomita K, Nitta K, et al. Revised equations for estimated GFR from serum creatinine in Japan. Am J Kidney Dis. 2009;53:982-92.

4. Koyama A, Igarashi M, Kobayashi M. Natural history and risk factors for immunoglobulin A nephropathy in Japan. Research Group on Progressive Renal Diseases. Am J Kidney Dis. 1997;29:526-32.

5. Moriyama T, Suzuki K, Sugiura H, Itabashi M, Tsukada M, Takei $\mathrm{T}$, et al. Frequency of renal disease in Japan: an analysis of 2,404 renal biopsies at a single center. Nephron Clin Pract. 2010;115:c227-36.

6. Nationwide and long-term survey of primary glomerulonephritis in Japan as observed in 1,850 biopsied cases. Research Group on Progressive Chronic Renal Disease. Nephron. 1999;82:205-13.

7. Chang JH, Kim DK, Kim HW, Park SY, Yoo TH, Kim BS, et al. Changing prevalence of glomerular diseases in Korean adults: a review of 20 years of experience. Nephrol Dial Transplant. 2009;24:2406-10.

8. Li LS, Liu ZH. Epidemiologic data of renal diseases from a single unit in China: analysis based on 13,519 renal biopsies. Kidney Int. 2004;66:920-3.

9. Gesualdo L, Di Palma AM, Morrone LF, Strippoli GF, Schena FP. The Italian experience of the national registry of renal biopsies. Kidney Int. 2004;66:890-4.

10. Rychlik I, Jancova E, Tesar V, Kolsky A, Lacha J, Stejskal J, et al. The Czech registry of renal biopsies. Occurrence of renal diseases in the years 1994-2000. Nephrol Dial Transplant. 2004;19:3040-9.

11. Goto M, Kawamura T, Wakai K, Ando M, Endoh M, Tomino Y. Risk stratification for progression of IgA nephropathy using a decision tree induction algorithm. Nephrol Dial Transplant. 2009;24:1242-7.

12. Goto M, Wakai K, Kawamura T, Ando M, Endoh M, Tomino Y. A scoring system to predict renal outcome in IgA nephropathy: a nationwide 10-year prospective cohort study. Nephrol Dial Transplant. 2009;24:3068-74.

13. Kim JK, Kim JH, Lee SC, Kang EW, Chang TI, Moon SJ, et al. Clinical features and outcomes of $\operatorname{IgA}$ nephropathy with nephrotic syndrome. Clin J Am Soc Nephrol. 2012;7:427-36.

14. McQuarrie EP, Mackinnon B, Stewart GA, Geddes CC. Membranous nephropathy remains the commonest primary cause of nephrotic syndrome in a northern European Caucasian population. Nephrol Dial Transplant. 2010;25:1009-10 (author reply 1010-1).

15. Yokoyama H, Taguchi T, Sugiyama H, Sato H. Membranous nephropathy in Japan: Analysis of the Japan Renal Biopsy Registry (J-RBR). Clin Exp Nephrol. 2012;16:557-63.

16. Shiiki H, Saito T, Nishitani Y, Mitarai T, Yorioka N, Yoshimura A, et al. Prognosis and risk factors for idiopathic membranous nephropathy with nephrotic syndrome in Japan. Kidney Int. 2004;65:1400-7.

17. Polanco N, Gutierrez E, Covarsi A, Ariza F, Carreno A, Vigil A, et al. Spontaneous remission of nephrotic syndrome in idiopathic membranous nephropathy. J Am Soc Nephrol. 2010;21:697-704.

18. Polanco N, Gutierrez E, Rivera F, Castellanos I, Baltar J, Lorenzo $\mathrm{D}$, et al. Spontaneous remission of nephrotic syndrome in membranous nephropathy with chronic renal impairment. Nephrol Dial Transplant. 2012;27:231-4.

19. Omokawa A, Komatsuda A, Nara M, Fujiwara T, Sato R, Togashi $\mathrm{M}$, et al. Renal biopsy in patients aged 80 years and older: a single-center experience in Japan. Clin Nephrol. 2012;77:461-7.

20. Yokoyama H, Sugiyama H, Sato H, Taguchi T, Nagata M, Matsuo $\mathrm{S}$, et al. Renal disease in the elderly and the very elderly Japanese: analysis of the Japan Renal Biopsy Registry (J-RBR). Clin Exp Nephrol. 2012 (in press).

21. Koyama A, Yamagata K, Makino H, Arimura Y, Wada T, Nitta $\mathrm{K}$, et al. A nationwide survey of rapidly progressive glomerulonephritis in Japan: etiology, prognosis and treatment diversity. Clin Exp Nephrol. 2009;13:633-50.

22. Yamagata K, Usui J, Saito C, Yamaguchi N, Hirayama K, Mase $\mathrm{K}$, et al. ANCA-associated systemic vasculitis in Japan: clinical features and prognostic changes. Clin Exp Nephrol. 2012;16: $580-8$.

23. Matsuo S, Yamagata K, Makino H, Arimura Y, Muso E, Nitta K, et al. The guideline for rapidly progressive glomerulonephritis. Jpn J Nephrol (in Japanese). 2011;53:509-55.

24. Covic A, Schiller A, Volovat C, Gluhovschi G, Gusbeth-Tatomir $\mathrm{P}$, Petrica L, et al. Epidemiology of renal disease in Romania: a 10 year review of two regional renal biopsy databases. Nephrol Dial Transplant. 2006;21:419-24.

25. Rivera F, Lopez-Gomez JM, Perez-Garcia R. Frequency of renal pathology in Spain 1994-1999. Nephrol Dial Transplant. 2002; 17:1594-602.

26. Heaf J, Lokkegaard H, Larsen S. The epidemiology and prognosis of glomerulonephritis in Denmark 1985-1997. Nephrol Dial Transplant. 1999;14:1889-97.

27. McQuarrie EP, Mackinnon B, Young B, Yeoman L, Stewart G, Fleming $\mathrm{S}$, et al. Centre variation in incidence, indication and diagnosis of adult native renal biopsy in Scotland. Nephrol Dial Transplant. 2009;24:1524-8.

28. Simon P, Ramee MP, Boulahrouz R, Stanescu C, Charasse C, Ang KS, et al. Epidemiologic data of primary glomerular diseases in western France. Kidney Int. 2004;66:905-8.

29. Wirta O, Mustonen J, Helin H, Pasternack A. Incidence of biopsy-proven glomerulonephritis. Nephrol Dial Transplant. 2008;23:193-200.

30. Briganti EM, Dowling J, Finlay M, Hill PA, Jones CL, KincaidSmith PS, et al. The incidence of biopsy-proven glomerulonephritis in Australia. Nephrol Dial Transplant. 2001;16:1364-7.

31. Utsunomiya Y, Koda T, Kado T, Okada S, Hayashi A, Kanzaki S, et al. Incidence of pediatric IgA nephropathy. Pediatr Nephrol. 2003;18:511-5. 